ARoueología Y SociedAd

№ 25, 2012: 115-142

ISSN: 0254-8062

RECIBIDO: ABRIL DE 2012

ACEPTADO: OCTUBRE DE 2012

\title{
LA OCUPACIÓN MOCHE EN LA MARGEN NORTE DEL VALLE BAJO DE MOCHE, COSTA NORTE DEL PERÚ
}

\author{
JORGE GAMBOA VeLÁSOUEZ \\ Proyecto Pañamarca, Área Monumental - Universidad Nacional Santiago Antunez de Mayolo \\ jgamboavelasquez@yahoo.com \\ JASON NESBITT \\ Universidad de Tulane, Departamento de Antropología. New Orleans, Louisiana \\ jnesbitt@tulane.edu edu
}

\section{RESUMEN}

Esta contribución trata sobre los asentamientos involucrados en el proceso de expansión agrícola Moche en la margen norte del Valle de Moche entre los siglos V a VIII d.C. Aun cuando las características de la ocupación Moche en esta área no son completamente conocidas actualmente se dispone de valiosos datos sobre los sistemas de irrigación y comunicación, la arquitectura residencial y monumental, y la cultura material local. La presente contribución, desarrollada a partir de prospecciones en diversas secciones del valle bajo de Moche y en excavaciones en el área de Caballo Muerto, revisa propuestas anteriores sobre la relación entre la ocupación Moche en la margen norte del valle bajo de Moche y el proceso de centralización política en Huacas de Moche, examinando la historia de una serie de comunidades y centros ceremoniales al interior de un paisaje que adquiría un nuevo rol para todos sus ocupantes.

Palabras clave: Costa Norte de Perú, Valle de Moche, civilización Moche, jerarquía de asentamientos, expansión agrícola.

\section{AbSTRACT}

This article discusses the settlements involved in agricultural expansion on the north side of the Moche Valley between the 5th and 8th centuries AD. While the characteristics of the Moche occupation in this area are not completely known, they do yield important data about irrigation systems, road networks, as well residential and monumental architecture. Furthermore, the local material culture, particularly pottery, serves to create a relative chronology of the sector. In this study, which is based on sites survey and excavations in various locations in the Lower Moche Valley, we revise proposals regarding a long-term relation between the north side of the lower valley and processes of political centralization in the area around the Huacas de Moche. Specifically, we focus on the history of a series of communities and ceremonial centers within a landscape that acquired a new role for all of its occupants.

KEYwoRDs: North Coast of Peru, Moche Valley, settlement hierarchies, agricultural expansion. 


\section{INTRODUCCIÓN}

Durante las dos últimas décadas un gran número de los proyectos arqueológicos desarrollados en la costa Norte de Perú han sido enfocados hacia el estudio de las poblaciones prehispánicas conocidas en conjunto como Moche. Estas investigaciones han ampliado nuestro conocimiento sobre la organización sociopolítica y la economía de sitios tan importantes como Sipán, San José de Moro, El Brujo, Huacas de Moche, Galindo, Guadalupito y Pañamarca, en los que se han registrado importantes concentraciones poblacionales y una jerarquización interna basada en el status y la especialización laboral de sus ocupantes, constituyéndose en capitales de organizaciones sociopolíticas centralizadas (Chapdelaine 2003; Moseley 1992: 183; Quilter 2002; Topic 1982: 273, 284).

Sin embargo, existen numerosos sitios menores cuyo estudio es vital debido a su posición intermediaria entre los centros urbanos y las zonas rurales dedicadas a la producción agrícola y pecuaria, pero también por su rol en la transformación del paisaje norcosteño y en la evolución de las sociedades complejas regionales. El presente artículo busca tratar esta temática, presentando los datos sobre la ocupación de la margen norte del valle bajo de Moche entre 400 y 700 d.C. y revisando los avances en la comprensión de ese proceso.

\section{El paisaje De la Margen norte Del Valle bajo De Moche}

La margen norte del valle bajo de Moche es un área llana de $21 \mathrm{~km}$ de largo delimitada al norte por el divortium aquarium con el Valle de Chicama y al sur por el río Moche, extendiéndose desde el sector de Caballo Muerto al este hasta las playas de Huanchaco y Chan Chan al oeste. El ancho del área varía entre $2 \mathrm{~km}$ en la conjunción con el valle medio y $15 \mathrm{~km}$ junto al Océano Pacifico entre Cerro Campana y la desembocadura del río Moche (ONERN 1973). ${ }^{1}$

El limite montañoso de la parte norte del valle bajo contiene tres cursos aluviales: las quebradas río Seco de Laredo, San Idelfonso en El Porvenir, y río Seco de El Milagro, vertientes que durante el Pleistoceno formaban parte de la cuenca baja del río Moche. Las tres quebradas son un refugio de vida silvestre debido a la formación de pequeños ecosistemas de «lomas» durante los meses de de invierno y especialmente en los años de lluvias ocasionadas por los fenómenos ENSO (El Niño-Southern Oscillation) (Nials et al. 1979a, 1979b). La actividad aluvial en las quebradas ha sido un elemento importante en la formación del paisaje y la ocupación humana del área, convirtiéndose en un constante factor de riesgo para las zonas más bajas dada la peculiar combinación para la zona de quebradas temporalmente activas, una planicie agrícola menor altitud y zonas de alta densidad demográfica. ${ }^{2}$

\section{SOCIEDADES DEL PERIODO INTERMEDIO TEMPRANO} E INICIOS DEL Horizonte Medio en el VAlle De Moche

El tema de la etnicidad en la costa Norte peruana durante el primer milenio de nuestra es un campo de debate relativamente reciente (Castillo y Donnan 1994; Makowski 1994, 1998). A continuación se presenta una reseña del estado actual del tema en el ámbito del valle de Moche.

1 La margen sur del valle bajo de Moche presenta un relieve distinto a la contraparte norteña, conteniendo una extensión de tierras agrícolas mucho menor que la margen norte.

2 Los fenómenos ENSO de mayor intensidad en el siglo XX fueron los de 1925, 1983 y 1998-1999. Uno de los Fenómeno El Niño mejor documentados para tiempos prehispánicos es el de 1100 d.C. (Nials et al. 1979a, 1979b; ver Chapdelaine (2000: 130) para su impacto en Huacas de Moche), que afectó fuertemente a la parte baja y media del valle durante la ocupación Chimú. 
Los estudios arqueológicos en el valle de Moche fueron iniciados en 1899 con los trabajos de Max Uhle (1915) en huacas de Moche. Un siglo después, las investigaciones sobre las sociedades complejas prehispánicas del valle han establecido que luego del apogeo de las sociedades formativas Cupisnique el área fue escenario de la formación de nuevas entidades sociopolíticas jerarquizadas, denominadas Virú (o Gallinazo) y Moche. La transición entre los Cupisnique y las sociedades del periodo Intermedio Temprano en el valle de Moche comprende el desarrollo del estilo Salinar, caracterizado por su cerámica oxidada con engobes Blanco sobre Rojo (Larco 1944) y mejor conocido localmente por el extenso sitio habitacional de Cerro Arena, situado en el lado sur del valle bajo (Brennan 1980; Mujica 1984).

Durante los primeros siglos de nuestra era los valles de la sección meridional de la costa Norte fueron ocupados por poblaciones portadoras de elementos culturales propios de las manifestaciones Salinar y Virú. Los grupos Virú han sido identificados por la asociación de cerámica con pintura resistente (Gallinazo Negativo) con los tipos cerámicos Castillo Modelado y Castillo Inciso (Bennett 1950; Fogel 1993; Strong y Evans 1952) El estilo cerámico Gallinazo Negativo comprende piezas mayormente modeladas, quemadas en atmósfera oxidante y con diseños en pintura negativa decorando figuras escultóricas estilizadas (Larco 1948; Fogel 1993). La cerámica Castillo Modelado e Inciso (Strong y Evans 1952) está representada por numerosas variantes de formas utilitarias, quemadas en atmósferas oxidantes poco controladas y con decoración basada en triángulos impresos, incisiones y aplicaciones modeladas sencillas. La reciente discusión sobre la validez de la identificación de una «cultura» Virú o Gallinazo en base a materiales cerámicos ha implicado el reconocimiento de que los tipos domesticos mencionados podrían haber sido producidos para uso cotidiano por diversas poblaciones de la región, implicando ello que la asociación de los productores y usuarios de estas formas de cerámica a formaciones políticas especificas debe ser investigada a partir de los patrones locales de producción y distribución de la cultura material (ver Millaire y Morlion 2009). En la actualidad es evidente que los grupos Virú y Moche compartían un número suficiente de técnicas de construcción monumental, arte, prácticas ceremoniales y tecnología productiva para ser considerados como grupos humanos con valores culturales comunes.

A partir de los siglos III y IV d.C. los linajes de elite y grupos de especialistas artesanales promovieron un nuevo estilo de arte público y mueble -conocido ahora como Moche-, basado en un complejo sistema visual de representaciones naturalistas del mundo social y natural de la época y reproducido en cerámica, textiles, metalurgia y decoración mural (Larco 2001; Pillsbury 2001; Uceda y Mujica 1994, 2004). La cerámica fina Moche presentaba engobes crema y rojo pre-cocción y pintura negra orgánica post-cocción (Donnan y McClelland 1999), siendo producida mediante moldeado y modelado (Uceda y Armas 1998). No obstante, varias formas de vasijas, especialmente las empleadas en la cocina y en el almacenamiento de productos, continuaron siendo elaboradas manualmente y fueron decoradas con técnicas simples de modelado, incisión y pintura comparables a las de la cerámica Castillo Modelado y Castillo Inciso.

Los mecanismos de integración política de los diversos grupos existentes en el valle de Moche a partir del siglo IV d.C. conforman un tema de investigación en proceso de definición. En el valle medio habría existido entre los siglos I a IV d.C. una entidad Gallinazo centralizada en el sitio de Cerro Orejas. Según Billman (2002) esta organización sociopolítica interactuaba activamente con las poblaciones del valle alto de Moche y las zonas serranas de Otuzco, ocurriendo posteriormente la emergencia de una nueva organización centralizada en huacas de Moche en el lado sur del valle bajo. Si bien las secuencias de desarrollo regional Moche han sido sujetas a cuestionamientos en las dos décadas pasadas, para el valle de Moche se acepta en términos generales la existencia de un periodo de emergencia y consolidación del poder político en huacas de Moche (Fases Moche III y IV) entre 400 a 650 d.C., con una etapa posterior de fragmentación geopolítica del valle entre 650 y 750/800 d.C. caracterizada por las ocupaciones Moche IV tardía de huacas de Moche y Moche V de Galindo (Topic 1982, 1991; Uceda et al. 2008). 


\section{El patrón de asentamiento Moche en LA MARGEN NORTE DEL VALLE BAJO DE MOCHE}

\subsection{Canales de irrigación}

La colonización prehispánica de la margen norte del valle bajo de Moche fue posible a través de la construcción de los canales primarios La Mochica, Moro y Vichanzao, los cuales presentaban sus bocatomas en el valle medio, al Este de Galindo y en proximidad al sector de Cerro Blanco. La Mochica y el Moro eran los canales más antiguos de la zona, posiblemente datando del Horizonte Temprano. El canal Vichanzao marcaba el límite de la expansión agrícola Moche sobre las planicies altas de El Porvenir, Florencia de Mora, y pampas La Esperanza (Fig. 1). Cabe señalar que la trayectoria de estos canales prehispánicos no permaneció inalterada a lo largo del tiempo, mostrando cambios progresivos y modificaciones parciales posiblemente como resultado de replanteamientos en el trazo y reparaciones ante daños causados por aluviones y desbordes (Moseley y Deeds 1982: 42, figuras 2.2 y 2.3). Durante la época prehispánica, al igual que ahora, los canales debieron haber servido como vías de transito pedestre realizado sobre sus bordes.

\section{Canal La Mochica}

Se trata del canal primario situado a menor elevación en la banda norteña del valle. Su construcción debió ser iniciada, junto a la del canal Moro, por las primeras entidades Cupisnique del valle durante el periodo Inicial (1600-1000 a.C.). En su primer tramo La Mochica permitía la irrigación de los sectores de Caballo Muerto (donde se localizaba la principal concentración de edificios públicos formativos del Valle de Moche) y huaca Sacachique (o huaca Caña). Durante el periodo Intermedio Temprano La Mochica fue ampliado hasta pampas La Esperanza, alcanzando una longitud de $31 \mathrm{~km}$ hasta el cauce del río Seco en proximidad a cerro La Virgen y pampa La Cruz de Huanchaco (Billman 2002: 379, 383; Moseley y Deeds 1982: 42).

El único fechado radiocarbonico reportado para la ocupación Moche en el lado norte del valle bajo de Moche procede de un ramal de La Mochica al noreste de Chan Chan denominado Canal A de Pampas La Esperanza, que produjo una fecha sin calibrar de $550 \pm 80$ d.C. (Pozorski 1987: Tabla 1), lo cual concuerda con la presencia de cerámica Moche III y mayormente Moche IV dentro del área. El Canal A pudo haber funcionado hasta mediados del periodo Intermedio Tardío, cuando fue parcialmente anulado por la construcción perpendicular a su cauce de dos nuevos canales secundarios Chimú (Pozorski 1987: 113).

\section{Canal Moro}

En la actualidad se denomina canal Moro al cauce artificial de agua localizado sobre el curso de La Mochica y que irriga la zona noroeste de Laredo. La sección más temprana del Moro sirvió inicialmente para cultivar las tierras al norte del canal La Mochica, extendiéndose hasta el actual límite ente los distritos de El Porvenir y Laredo.

\section{Canal Vichanzao}

El canal Vichanzao fue el componente más tardío del sistema hidráulico local Moche, alcanzando una longitud de $30 \mathrm{~km}$ desde su bocatoma hasta las planicies de El Porvenir, Florencia de Mora, el lado noreste de Pampas La Esperanza y la margen Sur de la quebrada río Seco. La construcción del canal Vichanzao no parece haber sido producto de un evento único, sino de una serie de elevaciones progresivas del curso de canales más antiguos. Moseley y Deeds (1982: 37) indican que la construcción del Vichanzao altero un cementerio Moche III localizado en la zona eriaza de la margen norte del valle bajo, lo cual indicaría una construcción entre 400 y 500 d.c. 


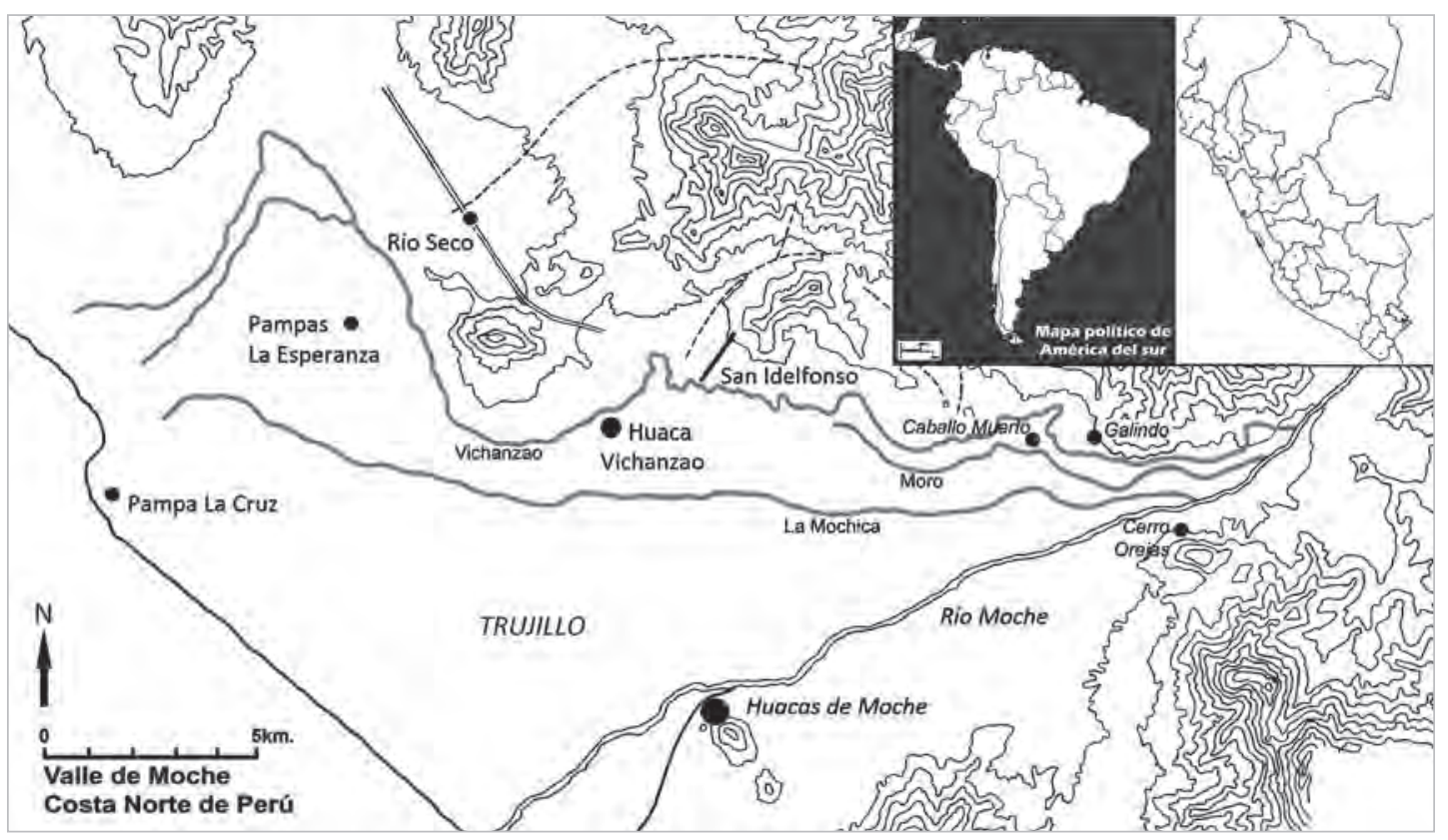

Figura 1. El valle de Moche y sitios mencionados en el texto.

\subsection{Complejo Caballo Muerto}

La información publicada sobre la presencia Moche en la zona de Laredo proviene principalmente de Caballo Muerto, un complejo de plataformas del periodo Formativo (Chauchat et al. 2006; Nesbitt et al. 2010; Pozorski 1976, 1983; Watanabe 1976). Diversas investigaciones al interior de este complejo han revelado la existencia de ocupaciones Salinar (200 a.C.-100 d.C.), Moche, y Chimú y Chimú-Inca (Chauchat y Guffroy 2003; Donnan y Mackey 1978: 40-41, 82-83, 364; Nesbitt 2013). En huaca de los Reyes, el edificio formativo mejor conocido del complejo (Pozorski 1976; Watanabe 1976), las evidencias de ocupación Moche son escasas. Sin embargo, la presencia Moche ha podido ser identificada en el resto de edificios formativos del sitio, incluyendo a las huacas Guavalito, Herederos Grande, Herederos Chica, La Cruz, y San Carlos (Pozorski 1976: 19, 31, 37, 42). En términos generales, el registro de la presencia Moche en Caballo Muerto indicaba una ocupación extensiva pero de características poco conocidas. Las investigaciones recientes de Jason Nesbitt en el área entre los años 2007 y 2008 han empezado a modificar este panorama mediante la documentación de una serie de materiales cerámicos Moche (con características de las Fases III y IV) en huaca Cortada, huaca La Cruz y huaca Curaca (Nesbitt 2013; Nesbitt et al. 2010).

Las excavaciones de Nesbitt en huaca Cortada produjeron abundantes materiales cerámicos Moche procedentes de un grueso depósito de escombros en la fachada oriental de la plataforma. Dentro de esa capa se recuperaron fragmentos de cerámica ceremonial Moche IV con decoración en línea fina, incluyendo partes de cuencos de pared expandida («floreros» o flaring-bowls), botellas de asa estribo, cántaros y vasijas retrato (Figs. 2 a-c). En huaca La Cruz se recuperó solo un fragmento de botella Moche IV, pero se pudieron registrar evidencias de actividades ceremoniales desarrolladas durante el Horizonte Medio, destacando el hallazgo de un contexto dedicatorio conformado por un cráneo humano y piezas de cerámica intencionalmente colocadas en la plaza delantera del edificio (Nesbitt 2010, 2013).

En huaca Curaca la limpieza de un pozo de huaquero permitió registrar una capa de desechos con fragmentos de cerámica Moche. La mayoría de los tiestos recuperados perteneció a vasijas con en- 

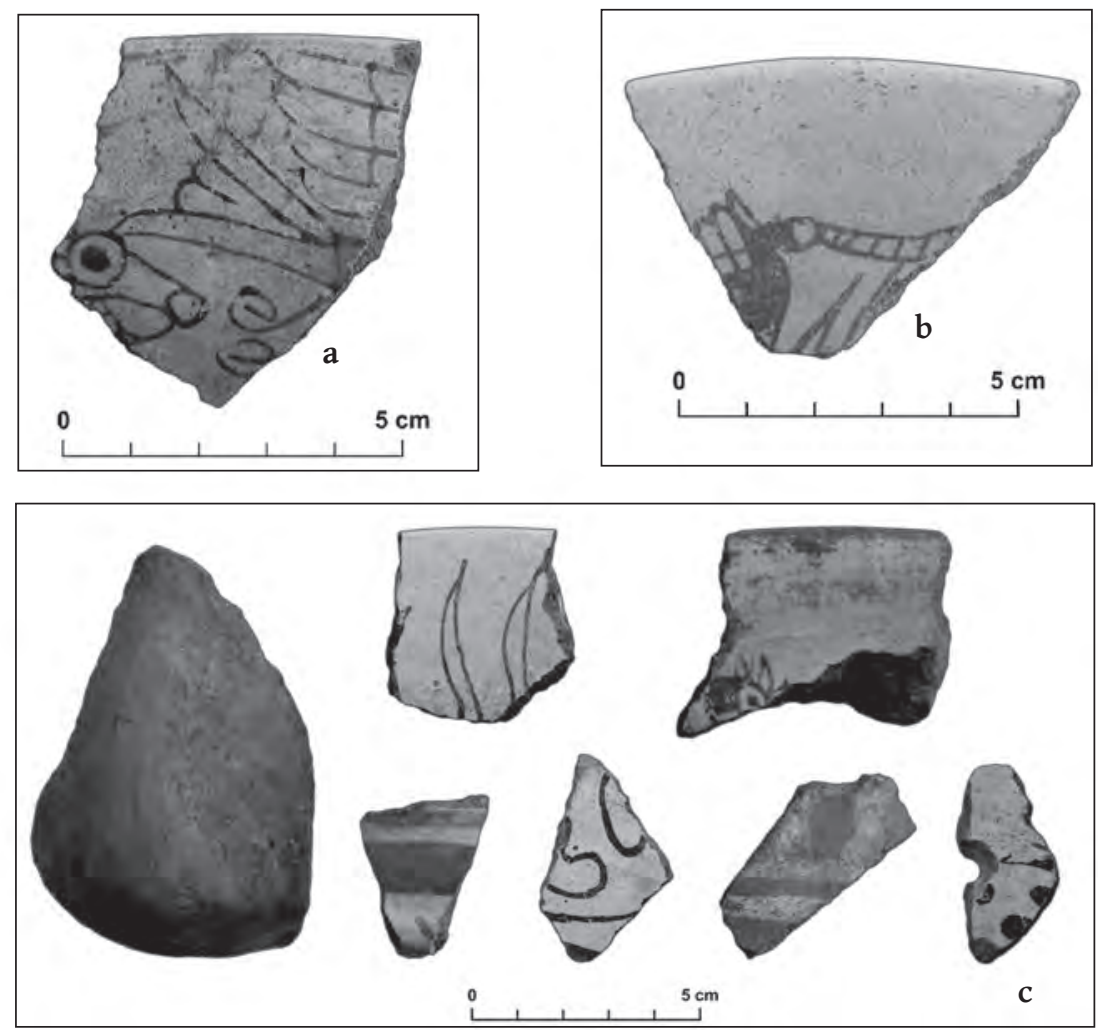

Figura 2. Cerámica Moche IV de huaca Cortada: a) Cuenco de borde expandido («florero») con representaciones zoomórficas, b) Cuenco de borde expandido ("florero») con representación antropomorfa, c) Fragmentos de cerámica fina (Fotos: J. Nesbitt 2008).

gobes rojo y crema, encontrándose también fragmentos de piezas con pintura en línea fina. Aunque la muestra cerámica de huaca Curaca contuvo una proporción menor de fragmentos de cuencos de pared expandida en comparación a aquella procedente de la cercana huaca Cortada (Fig. 3), las asambleas cerámicas post-formativas de ambos edificios estuvieron conformadas mayormente por alfarería Moche decorada. En las excavaciones conducidas alrededor de huaca Cortada la cerámica de las capas post-formativas careció de decoración pintada o moldeada, perteneciendo a formas utilitarias y domesticas como cántaros y ollas de pasta naranja, acabado sencillo y cocción oxidante, con presencia ocasional de piezas con engobes crema al exterior. Las diferencias entre las muestras cerámicas de las plataformas y la planicie tienden a indicar el desarrollo de actividades distintas por la población del área durante una ocupación que puede ser asignada a la segunda mitad del periodo

Figura 3. Cerámica Moche IV de huaca Curaca (Fotos: J. Nesbitt, 2008).

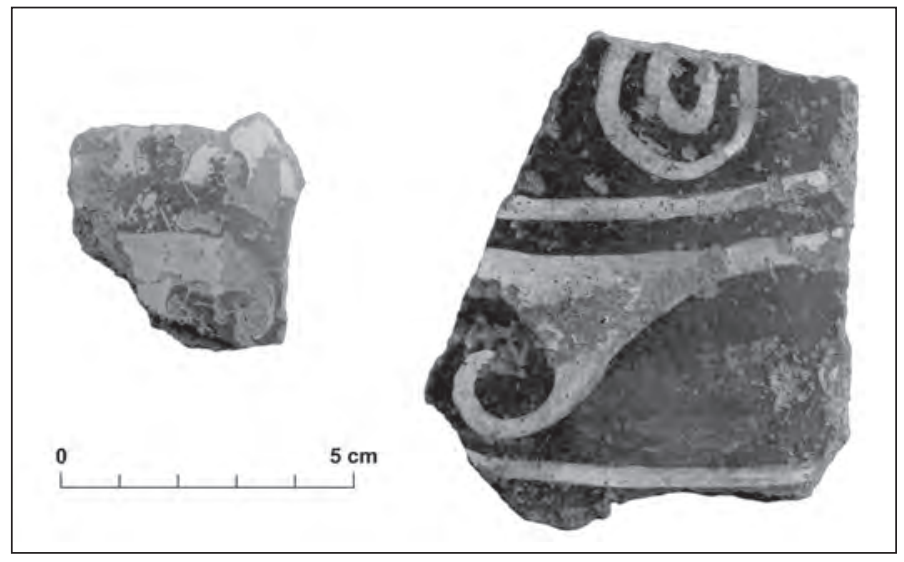


Intermedio Temprano. El predominio de vasijas decoradas Moche en algunas plataformas indica que la reocupación de esos edificios fue significativa, originándose posiblemente en el desarrollo de actividades ceremoniales a través de las cuales esos monumentos fueron reconocidos como lugares asociados a la ancestralidad de las comunidades locales Moche.

El único entierro Moche reportado para Caballo Muerto fue excavado en 1974 por los miembros del Chan Chan-Moche Valley Project (CCMVP) al interior de un recinto localizado en el flanco noroeste del cerro donde se ubica Huaca Guavalito correspondiendo a una mujer joven sepultada en una fosa simple (Donnan y Mackey 1978: 22, 81-85). El cuerpo estuvo colocado en posición decúbito dorsal, orientado de NE a SW, con la cabeza dispuesta hacia el Oeste y la mano derecha sobre la región pélvica. Las ofrendas mortuorias de este personaje consistieron en tres láminas circulares de cobre (dobladas y colocadas en la boca y junto a cada mano), tres cántaros finos con pintura crema, roja y negra orgánica dispuestos junto a las extremidades inferiores, y una botella de asa estribo Moche III localizada junto al cráneo. Está última pieza estuvo decorada con la representación pictórica de animales terrestres estilizados, correspondiendo posiblemente a felinos.

\subsection{San Idelfonso}

Este sitio se localiza en el distrito El Porvenir a $6 \mathrm{~km}$ al noreste de la ciudad de Trujillo, extendiéndose sobre una llanura delimitada al norte por el cerro San Idelfonso y al noroeste por la quebrada homónima (Fig. 4). La vegetación y fauna silvestres en la llanura son escasas, pero el área próxima a la quebrada San Idelfonso presenta especies vegetales xerofíticas (Tillandsia sp. y cactáceas) y una fauna silvestre compuesta por caracoles terrestres (Scutalus sp.), aves (Coragyps atratus: gallinazo de cabeza negra, Bubulcus ibis: garza, Athene cunicularia: búho de arena, etc.), reptiles (Familias Teiidae y Gekkonidae) y mamíferos (Lyacalopex sechurae: zorro costeño y Pillotis sp.: ratón). El incremento de lluvias durante la ocurrencia del fenómeno de El Niño permite un notable aumento de la vida silvestre en la zona, con la aparición de especies vegetales como Prosopis pallida (algarrobo) y Capparis angulata

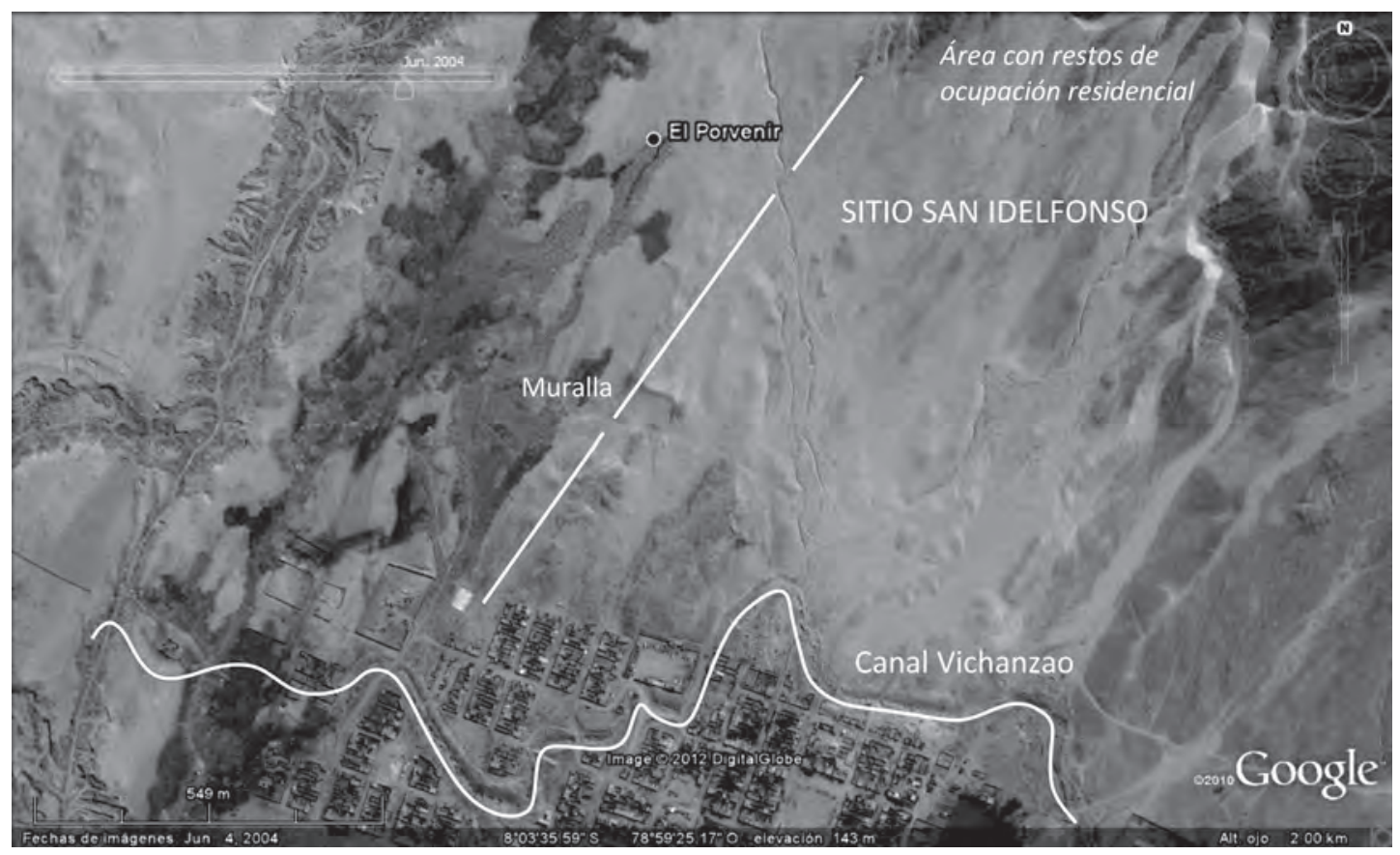

Figura 4. Foto satelital de San Idelfonso (Google Earth 2012). 
(zapote). Según los pobladores locales, hasta la primera mitad del siglo XX la quebrada era ocupada estacionalmente por venados (Odocoileus virginianus) y pumas (Felis concolor).

La presencia del sitio San Idelfonso en la literatura arqueológica es escasa, habiendo sido reconocido por Rodríguez Suy Suy en 1971 como uno de los asentamientos prehispánicos asociados asociados al canal Vichanzao. El sitio fue posteriormente inventariado por Ravines y Matos (1983), quienes no especificaron su filiación cronológica. La estructura principal del sitio es un amurallamiento de $980 \mathrm{~m}$ de longitud, que se origina junto al Canal Vichanzao y continúa hasta la base del Cerro San Idelfonso. Los datos presentados a continuación corresponden a la prospección del área realizada por Jorge Gamboa en los años 1999 y 2002-2004 (Gamboa 2006; Gamboa y Nesbitt 2010).

El primer segmento del muro alcanza los $500 \mathrm{~m}$ de longitud y fue elaborado con piedras angulosas y cantos rodados, a modo de un grueso muro de doble cara ( 2 a 2,50 m de espesor) con relleno interno de tierra y cascajo. La segunda sección de la muralla mide $480 \mathrm{~m}$ de largo con ancho promedio de $2 \mathrm{~m}$ y fue elaborada con adobes lisos y estriados elaborados en moldes de madera tallada o de cañas (Figs. $5 \mathrm{y}$ 6). A partir de 1998, los pobladores del área han afectado esta parte de la estructura, extrayendo adobes para la construcción de viviendas. En los cortes se observa que el muro presenta hiladas alternas de soga y cabeza, con paramentos enlucidos y niveles de sedimentos producidos por lluvias. Entre los adobes desmontados (con dimensiones de 33 x 20 x 13 cm, 30 x 20 x 14 cm y 28 x $19 \times 12 \mathrm{~cm}$ ) se encontraron varios tipos de marcas incisas, identificándose ejemplares con punto central, línea diagonal, o la combinación de ambos motivos. La superficie del terreno a ambos lados de la muralla presenta tiestos de cocción oxidante pertenecientes a vasijas domesticas llanas y a piezas con engobe rojo y crema. La altura original de la sección de adobes de la muralla es desconocida, pero considerando una elevación mínima de $1 \mathrm{~m}$ esta construcción habría alcanzado un volumen de $960 \mathrm{~m}^{3}$, equivalentes a 114.200 adobes (promedio de 119 adobes de $30 \times 20 \times 14 \mathrm{~cm}$ por cada metro cúbico). La presencia de adobes marcados en San Idelfonso indicaría que la elaboración de estos materiales pudo ser realizada por distintos grupos de trabajadores auspiciados por una autoridad central, con cada marca identificando la producción de un grupo corporativo (Hasting y Moseley 1975).

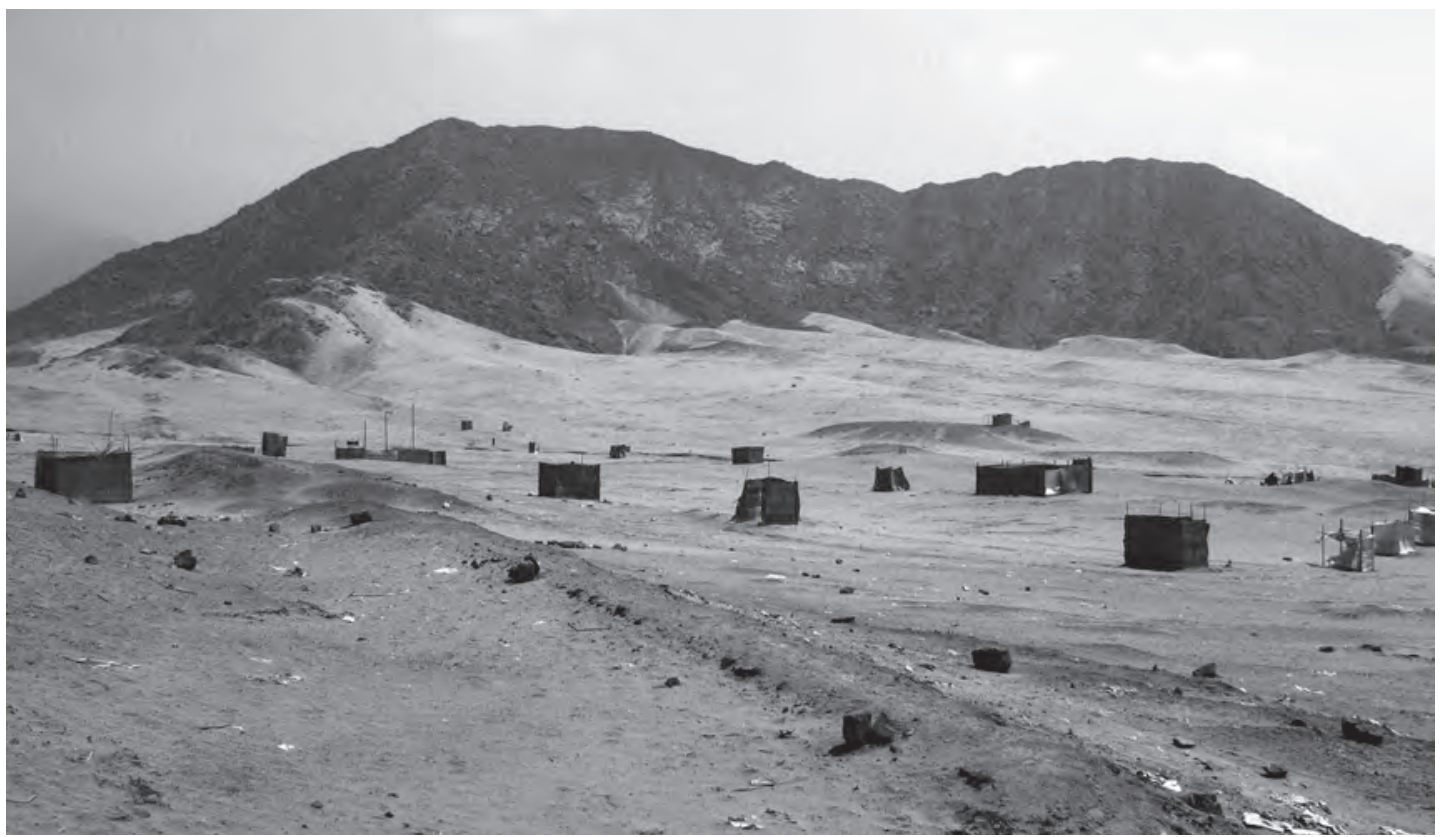

Figura 5. Sección de adobe de muralla en San Idelfonso (Foto: J. Gamboa, 2008). 


\section{Figura 6. Adobes marcados del sitio San Idelfonso (Foto: J. Gamboa, 2008).}

En la superficie del flanco sur del cerro San Idelfonso se encuentran restos malacológicos (Donax sp., Turbo níger, Choromytilus chorus, Fisurella crassa, y Scutalus sp.) y concentraciones de fragmentería cerámica

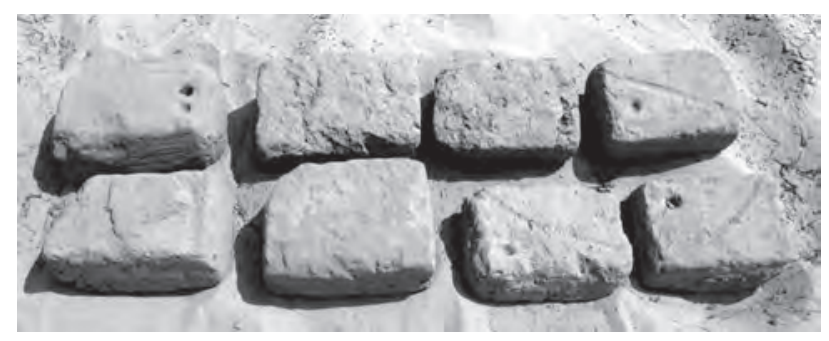
llana y decorada, piruros de arcilla, ceniza y grumos de tierra calcinada, y un elemento de molienda (batán) formado por un canto aluvial aplanado. La presencia de estos elementos indicaría la función domestica de esa parte del asentamiento. Dada la cercanía del canal Vichanzao y el ecosistema de quebrada, las actividades económicas desarrolladas por los ocupantes del sitio debieron incluir la producción agrícola y la explotación de recursos vegetales y animales en la zona montañosa.

La cerámica decorada y domestica del sitio comparte características formales y técnicas con la producción alfarera Moche IV en huacas de Moche (Chapdelaine 1998, 2003; Chapdelaine et al. 1997). La mayoría de fragmentos de cerámica presentes en superficie corresponden a vasijas empleadas en la cocción y almacenamiento de alimentos y productos, identificándose cántaros de cuello divergente y base anular, cántaros de cuello convexo, ollas de cuello corto divergente, y tinajas de borde reforzado. Algunos bordes de cántaros muestran «marcas de alfarero» en forma de incisiones cortas (Fig. 7a). La cerámica decorada Moche observada en superficie incluye botellas de asa estribo y de asa lateral, cántaros pintados con motivos geométricos, cuencos y figurinas. Un elemento significativo para proponer una cronología relativa del sitio fueron los fragmentos de botellas de asa estribo hallados en proximidad al muro de adobes. Uno de estos fragmentos correspondió a una pieza con la representación de una «escena de carrera ritual» (Hocquenghem 1987: Figs. 51, 54, 55) (Fig. 7b). Una proporción menor de fragmentos observados en el sitio pertenecen al estilo Moche V (Figs. 7c y 7d), como en el

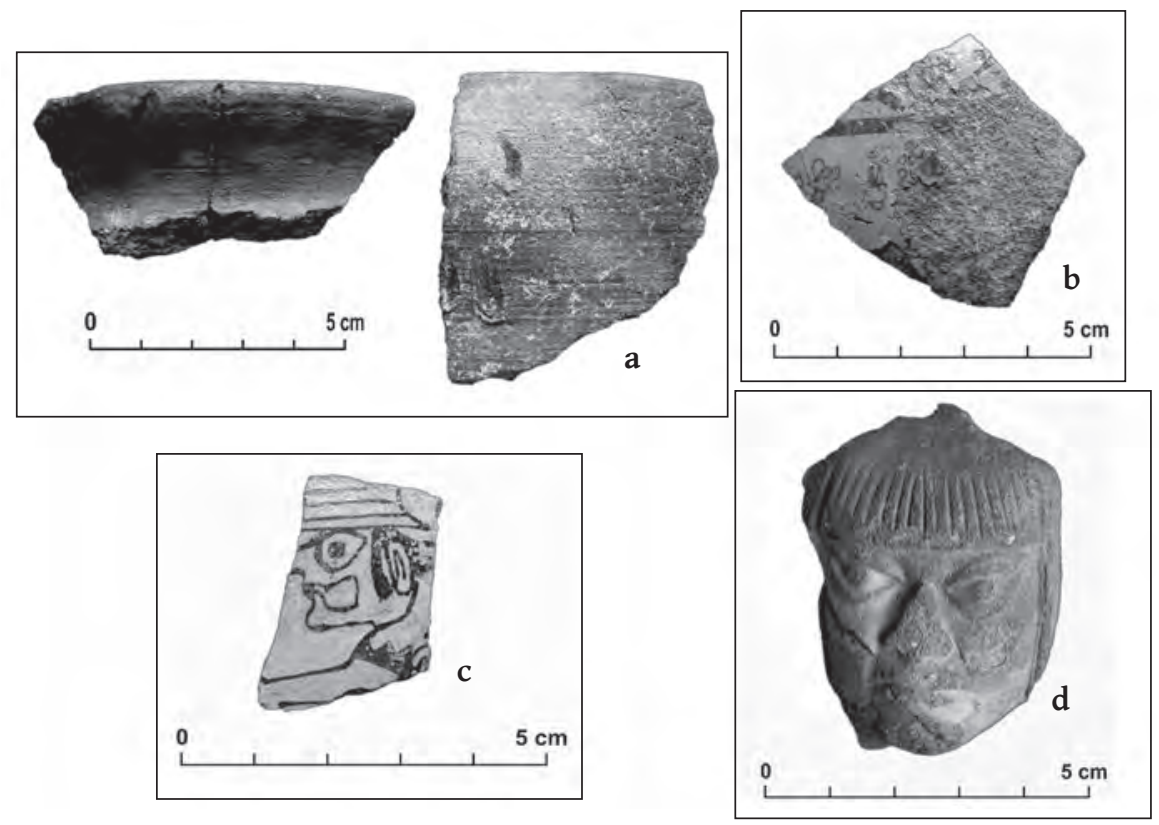

Figura 7. a) Bordes de olla y cántaro con marcas de fabricante, b) Fragmento de botella Moche IV, c) Fragmento de botella Moche V, d) Figurina femenina moldeada (Fotos: J. Gamboa). 
caso de un fragmento de botella de asa estribo de cocción reductora incompleta mostrando la representación pictórica de un personaje participante en una «escena de navegación» (Donnan 1978: Fig. 163). La ocurrencia de cerámica con iconografía en línea fina indica el acceso de algunos ocupantes del sitio a productos de alta calidad, los cuales debieron ser transportadas al área a través de redes de intercambio de bienes de prestigio con otros asentamientos Moche.

El estudio de Colleen Beck (1979: 79, 82) sobre las vías de comunicación prehispánica en el valle de Moche proporciona valiosos datos sobre las rutas alrededor de San Idelfonso (Fig. 8), sitio que fue identificado por Beck como un muro Moche III y IV vinculado a la trayectoria de tres caminos. El Camino 1 corría en paralelo y al oeste de la muralla, conduciendo a la entrada a quebrada de León, punto donde se unía al extremo NW del Camino 2, el cual atravesaba la sección de adobes del muro. El Camino 3, orientado de este a oeste, también pasaba transversalmente sobre la muralla y se unía al extremo sur del Camino 2. Los Caminos 2 y 3 pudieron ser usados en tiempos prehispánicos tardíos, apareciendo concentraciones de fragmentos de cerámica Chimú al noroeste de la unión de ambas rutas (Beck 1979: Fig. 13, Sitio A). Beck indicó que el área de San Idelfonso pudo adquirir una especial importancia para el tráfico de las poblaciones Moche y Chimú situadas entre Laredo y el resto del valle bajo. Esta ruta incluía a los Caminos 3, 4, 5 y 9, que pudieron conformar la principal vía de acceso a Laredo, continuando al Oeste hacia huaca Vichanzao y Cerro Cabras, punto donde se iniciaba el camino que conducía a la margen sur del valle de Chicama.

\subsection{Huaca Vichanzao (Huaca Florencia de Mora)}

Este sitio con arquitectura monumental se localiza junto al curso medio del canal Vichanzao en la parte central de la margen norte del valle bajo de Moche (Figs. 9 a y b). En 1973 los integrantes del CCMVP registraron el sitio con el nombre de huaca del Arenal, observando la presencia de cerámica Moche IV y V, arquitectura con adobes marcados, áreas con restos de actividades residenciales y un

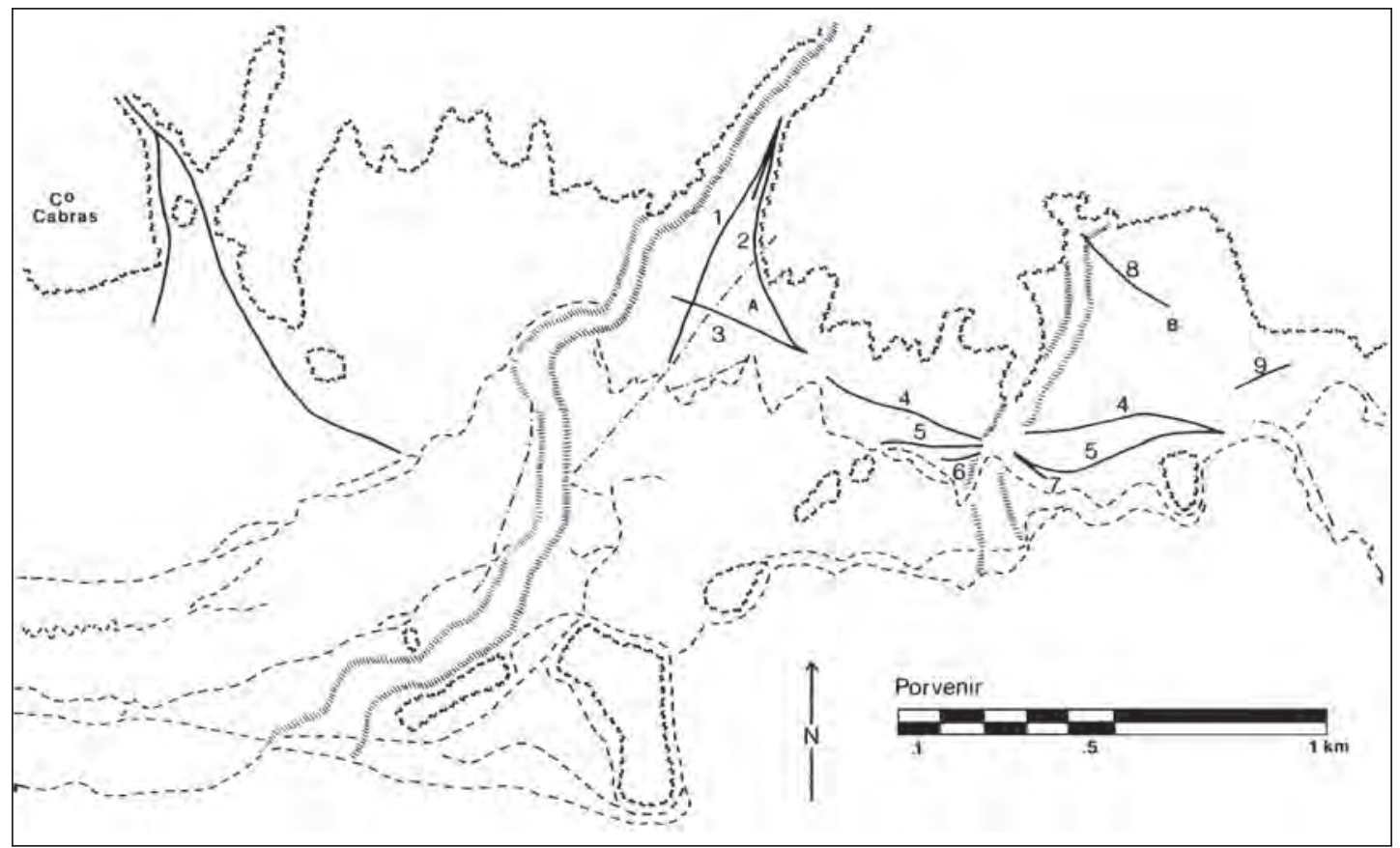

Figura 8. Caminos prehispánicos en el área de San Idelfonso (Beck 1979: Fig. 13). 

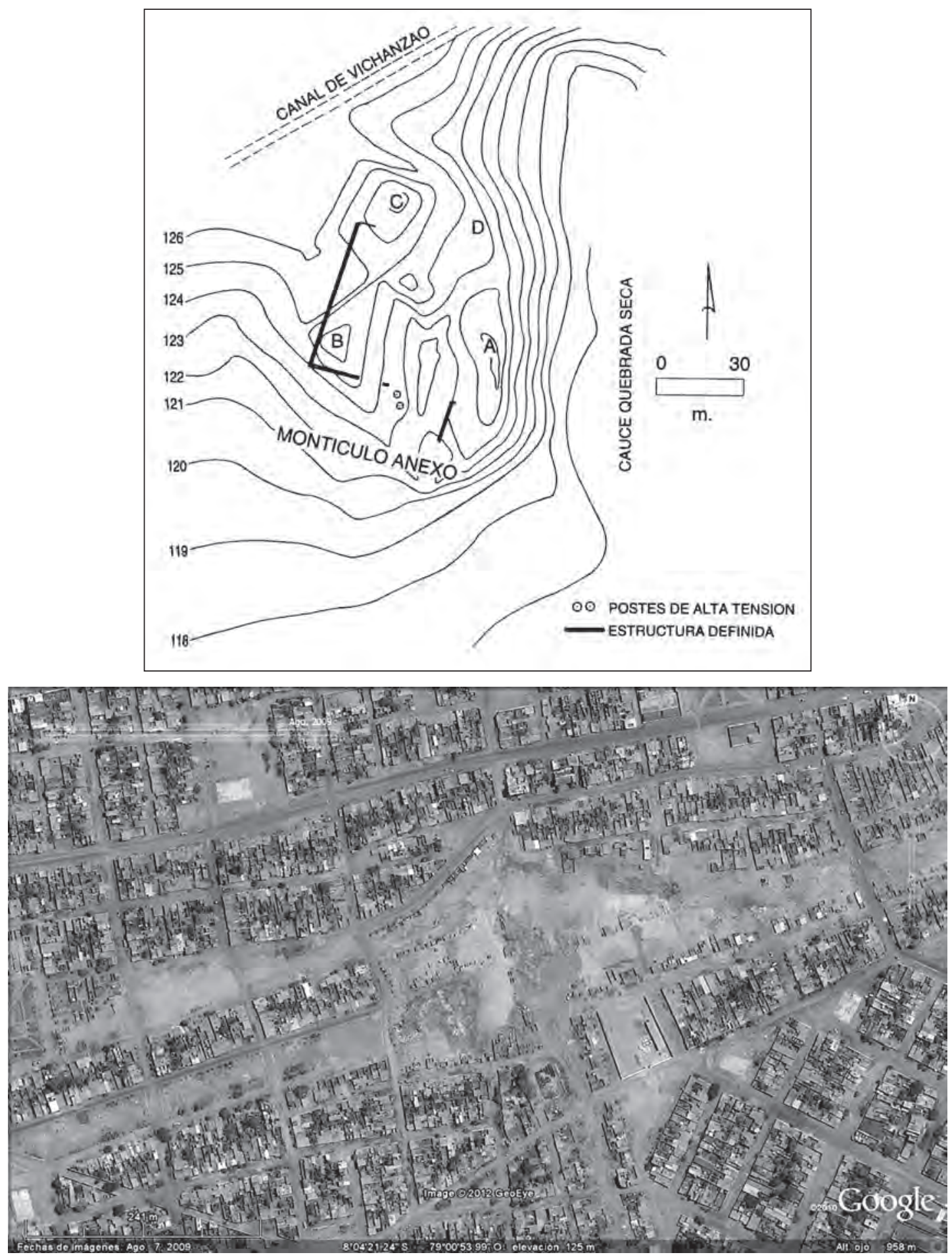

Figura 9. Arriba: Plano de huaca Vichanzao (Pérez 1994);

Abajo: Expansión urbana alrededor de huaca Vichanzao (Google Earth 2009). 
Figura 10. Superior: Rellenos de adobes tramados en Huaca Vichanzao (Ramírez y Wong 1984: Foto 6). Inferior izquierda: Botella Moche IV (Pérez 1994). Inferior derecha: Adobes marcados (Ramírez y Wong 1984: Foto 7).

camino prehispánico (Pérez 1994: 228). Una década después, Eulalia Ramírez y María Wong (1984) de la Universidad Nacional de Trujillo (UNT) realizaron una serie de pozos de prueba, documentando la superposición de rellenos de adobes tramados (Figs. 10a y 10c), pisos de barro intercalados con rellenos de arena, y capas de sedimentos ocasionados por fuertes precipitaciones. En uno de los cateos se recupero una botella escultórica representando a un personaje antropomorfo con cabeza de zorro (Pérez 1994; Ramírez y Wong 1984), pieza que muestra rasgos característicos del estilo cerámico Moche IV de huacas de Moche (Fig. 10b).

En 1986 el Instituto Nacional de Cultura-Filial La Libertad intervino en el sitio ante la depredación cau-
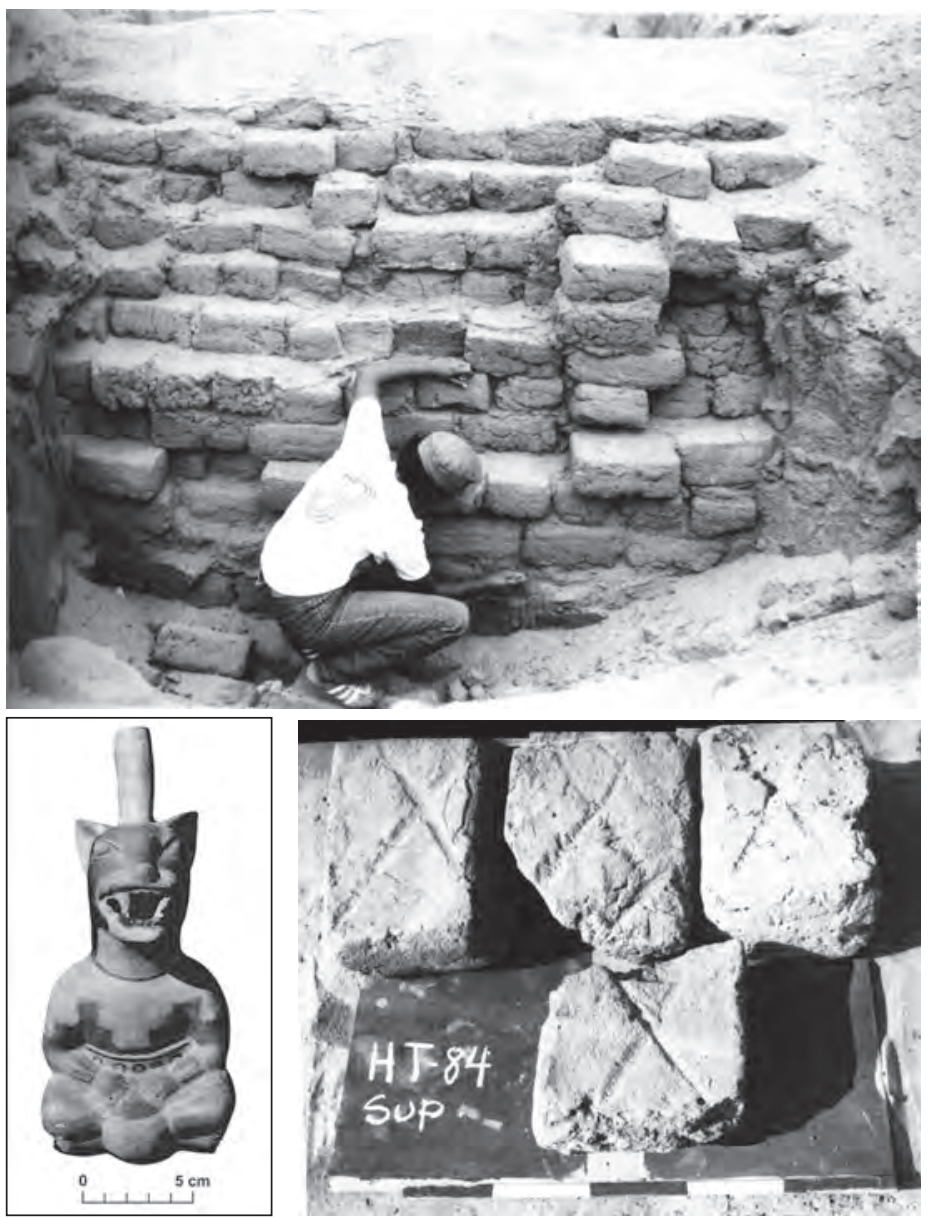
sada por los pobladores asentados alrededor del sitio arqueológico. Estos nuevos trabajos permitieron registrar varios sectores de una plataforma construida con adobes lisos o estriados y con piedras canteadas (estás últimas empleadas en las esquinas del edificio). La plataforma presentaba paramentos enlucidos y pintados en rojo, blanco y amarillo, reportándose nuevamente fragmentos de cerámica Moche IV y, en menor cantidad, Moche III en rellenos constructivos y pisos (Pérez 1994: 231-233). Las labores del Instituto Nacional de Cultura en 1987 permitieron determinar la planta cuadrangular del edificio principal, uno de cuyos lados alcanzaba los $87 \mathrm{~m}$ de longitud. Un detalle importante de los trabajos de 1986 y 1987 fue el registro de 130 «marcas de fabricante» formalmente distintas, observadas en adobes recuperados en excavaciones y áreas afectadas por saqueadores.

Una referencia etnohistórica a huaca Florencia de Mora y al sector colindante de Mampuesto fue publicada posteriormente por Rischar et al. (1998: 25), autores que hicieron referencia a la presencia de campos de cultivo prehispánicos localizados en las terrazas aluviales de la margen izquierda de la quebrada de San Idelfonso.

\subsection{Pampas La Esperanza}

Las referencias al sitio de Pueblo Joven de pampas La Esperanza son proporcionadas por Beck (1979: 90-92), quien describe una concentración de 40 estructuras de piedra ubicada en la parte norcentral de pampas La Esperanza cerca al área de río Seco, indicando tanto la existencia de un estudio inédito 
del sitio como una asociación con canales de irrigación y materiales Moche V (Beck 1979: Nota 22). Adicionalmente, Beck (1979: 91) indicó la existencia de pequeñas estructuras Moche III-IV en Pampas La Esperanza.

Para la zona sur de pampas La Esperanza, Beck (1979: 91, Fig. 16) refiere la presencia del Camino 1, carente de muros de piedra y que corría de SE a NW en un nivel del terreno inferior al curso del canal Vichanzao. Esta vía pudo articular durante la ocupación Moche la zona al sur de huaca Vichanzao, Cerro Cabras, y el abra que conducía a Chicama. El Camino 1 fue alterado por la construcción del sitio de Pueblo Joven y por la trayectoria de varios canales (Beck 1979: 91-92), pudiendo haberse hallado abandonado en tiempos Chimú al hallarse en medio del área de canales situados en la parte septentrional de Chan Chan.

En el sector norte de pampas La Esperanza aparecen diversos componentes arqueológicos fuertemente afectados por el crecimiento urbano de los distritos La Esperanza y El Milagro, hecho ya anotado en la década de 1970 por el CCMVP y el Proyecto Riego Antiguo (PRA). En 1997 uno de los sectores con arquitectura prehispánica asociada a canales de irrigación y campos de cultivo fue investigado por un equipo de la UNT dirigido por Carlos Deza, reportándose una estructura de carácter residencial asociada a materiales cerámicos Moche IV y en menor proporción Moche V (Cossio et al. 1997). Este conjunto habitacional rural fue elaborado con muros de cantos rodados y pisos de barro elaborados sobre rellenos de tierra y desechos, presentando un patio central cuadrangular y provisto en la esquina norte de una pequeña plataforma con tres escalones de acceso (Fig. 11). Otros componentes de la vivienda fueron varios recintos de planta cuadrangular y pequeños ambientes (de 1,5, 2 y $3 \mathrm{~m}^{2}$ de espacio interior) identificados como depósitos. El patio y los espacios colindantes presentaban restos orgánicos y áreas de quema y/o preparación de alimentos, actividad que incluyo actividades de molienda en un batán. La cerámica documentada comprendía una alta proporción de ollas y cántaros domésticos con base pedestal.

La planificación de esta residencia es parcialmente similar a la de los conjuntos habitacionales menores de huacas de Moche y Galindo. Aunque en todos ellos es recurrente la presencia del patio como elemento nuclear de la vivienda y como espacio de cocina, también aparecen diferencias en la morfología de esos espacios posiblemente originadas en el status o identidad de los residentes. En huacas de Moche los patios centrales de las residencias presentaban banquetas laterales y eran accedidos mediante corredores que los conectaban a las calles de la red urbana. En Galindo se encuentran casos de viviendas con dos patios, uno dedicado a la preparación de alimentos y otro con banquetas techadas (Bawden 1982: 310). Un rasgo particular de la vivienda rural de pampas La Esperanza es la presencia de depósitos ubicados en diversos puntos del patio y no en hileras contiguas como en los conjuntos habitacionales de huacas de Moche.

Figura 11. Vivienda de Pampas La Esperanza (adaptado de Cossio et al. 1997: Lám. 4).

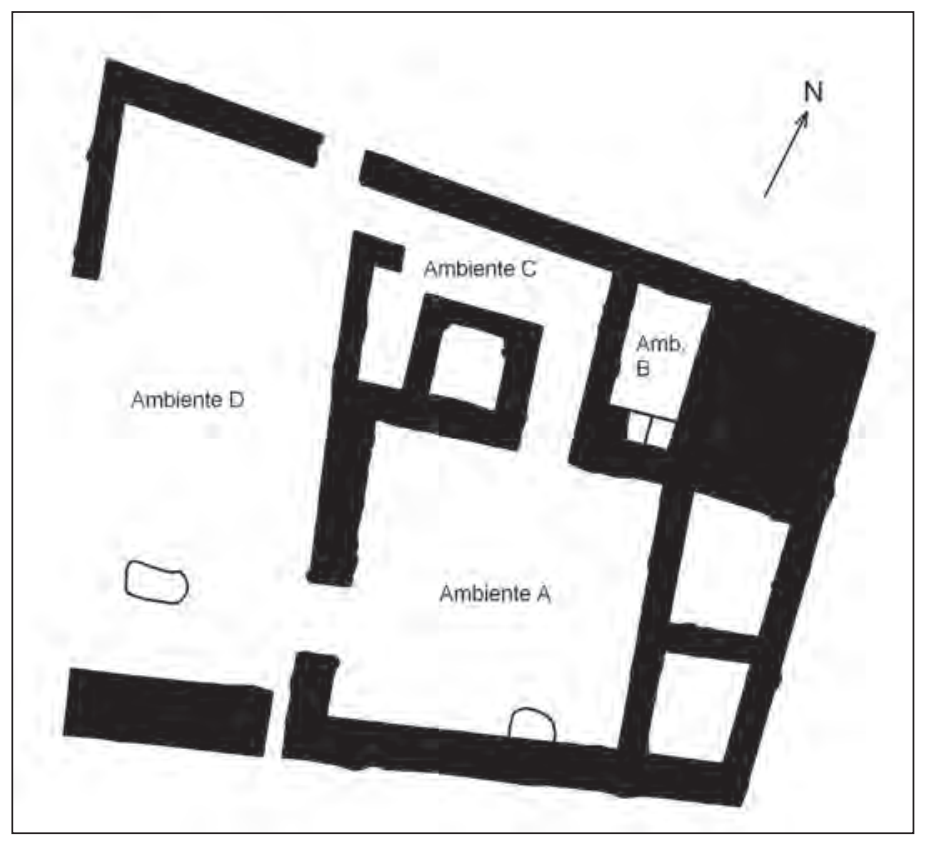




\subsection{Río Seco y los caminos entre cerro Campana y cerro Cabras}

Durante el periodo Intermedio Temprano el espacio entre los cerros Campana y Cabras fue empleado como la principal ruta de tráfico hacia Chicama (Beck 1979: 82-89, Figs. 14-15). Esta ruta fue posteriormente modificada por los Chimú, quienes construyeron el canal intervalle La Cumbre y la muralla de piedra que corre entre cerro Campana y el flanco este de cerro Cabras (Fig. 12).

En esta sección periférica del valle bajo de Moche, Beck identificó una serie de caminos con trayectoria de SE a NW, que, en varios casos, corren en paralelo. Los Caminos 2 y 5 fueron las vías principales del área. El Camino 2 se hallaba en el extremo sur de la ruta y se iniciaba cerca al cauce de la quebrada Río Seco, pudiendo haberse conectado originalmente con la ruta este-oeste que cruzaba el sitio de San Idelfonso. El Camino 1 corría por los flancos este y sur de Cerro Cabras, dirigiéndose hacia el área de huaca Vichanzao, mientras que el Camino 6 habría marcado el ingreso hacia la parte alta de la quebrada Río Seco. El Camino 5, que se inicia en el abra al este de cerro Cabras, funcionó como la vía principal de la zona durante el periodo Intermedio Temprano, siendo construido sobre la ruta demarcada previamente por los cercanos Caminos 3 y 4 . En proximidad al Camino 4 se encuentra una estructura rectangular de piedra excavada por Bankes (1971: 120) y que pertenecería al periodo Cupisnique con reocupaciones Virú/Gallinazo y Moche. La proximidad entre el Camino 4 y el edificio Cupisnique indica que la ruta intervalle al este de Cerro Cabras habría estado en uso durante el Horizonte Temprano.

El Camino 5 se asociaba al asentamiento Moche de río Seco, identificado por Beck (1979: 84-85) como Sitio B o H1929, ocupado en tiempos Moche y durante el periodo Intermedio Tardío. Este camino formaba parte de la ruta Moche hacia Chicama (Beck 1979: fig. 14), debiendo haberse conectado al norte con los Caminos 7 y 8 , que muestran una orientación similar y se proyectaban hasta la margen sur del valle bajo de Chicama. Río Seco cubre un área de $260 \mathrm{~m}$ por $60 \mathrm{~m}$ (Fig. 13) y comprende dos hileras de recintos rectangulares ubicados a ambos lados del Camino 5. Dos estructuras fueron excavadas por Bankes (1971), quien reportó fragmentos de cerámica Moche IV, y en menor proporción Moche III y Chimú. Más recientemente, Deza y Rodríguez (2003: 270-273) prospectaron el sitio, señalando que la mayoría de estructuras fueron elaboradas con muros dobles de cantos rodados con rellenos internos de tierra, ubicando también restos de construcciones de adobes.

El primer grupo de estructuras de río Seco se concentra en el lado este del Camino 5, comprendiendo dos conjuntos arquitectónicos con acceso directo al camino y con ambientes distribuidos alrededor de patios. El segundo grupo se localiza al oeste del camino y esta conformado por dos grupos alargados de recintos contiguos que cubren los extremos de esa parte de la aldea. Un último grupo de estructuras está conformado por recintos rectangulares ubicados al oeste del camino que pudieron servir como corrales para camélidos. En la superficie del área aparecen fragmentos de vasijas domesticas, cántaros escultóricos, figurinas moldeadas y botellas de asa estribo y de pico recto con asa lateral, así como restos de especies malacológicas y mamíferos terrestres. Deza y Rodríguez (2003: 268) sugirieron el probable uso del sitio como un puesto de control territorial y aprovisionamiento para el trafico caravanero intervalle.

\subsection{Pampa La Cruz de Huanchaco (La Poza)}

Este extenso complejo arqueológico comprendía los Montículos 1 y 2, construcciones de carácter residencial, muros perimetrales de piedra, y áreas con evidencias de campos de cultivo y canales de riego. Los trabajos desarrollados por la UNT en Pampa La Cruz durante las décadas de 1980 y 1990 condujeron al registro de una secuencia ocupacional prehispánica de hasta tres metros de profundidad, con capas asociadas a materiales cerámicos Blanco sobre Rojo, Castillo Modelado y Castillo Inciso (Barr 2000: 17-18; Mendoza et al. 1989; Sánchez y Tinta 1990). Uno de los sectores excavados en 1989 presentó un ambiente de 6 × 2 m (denominado por sus excavadores como «recinto abastecedor»), ubicado a 


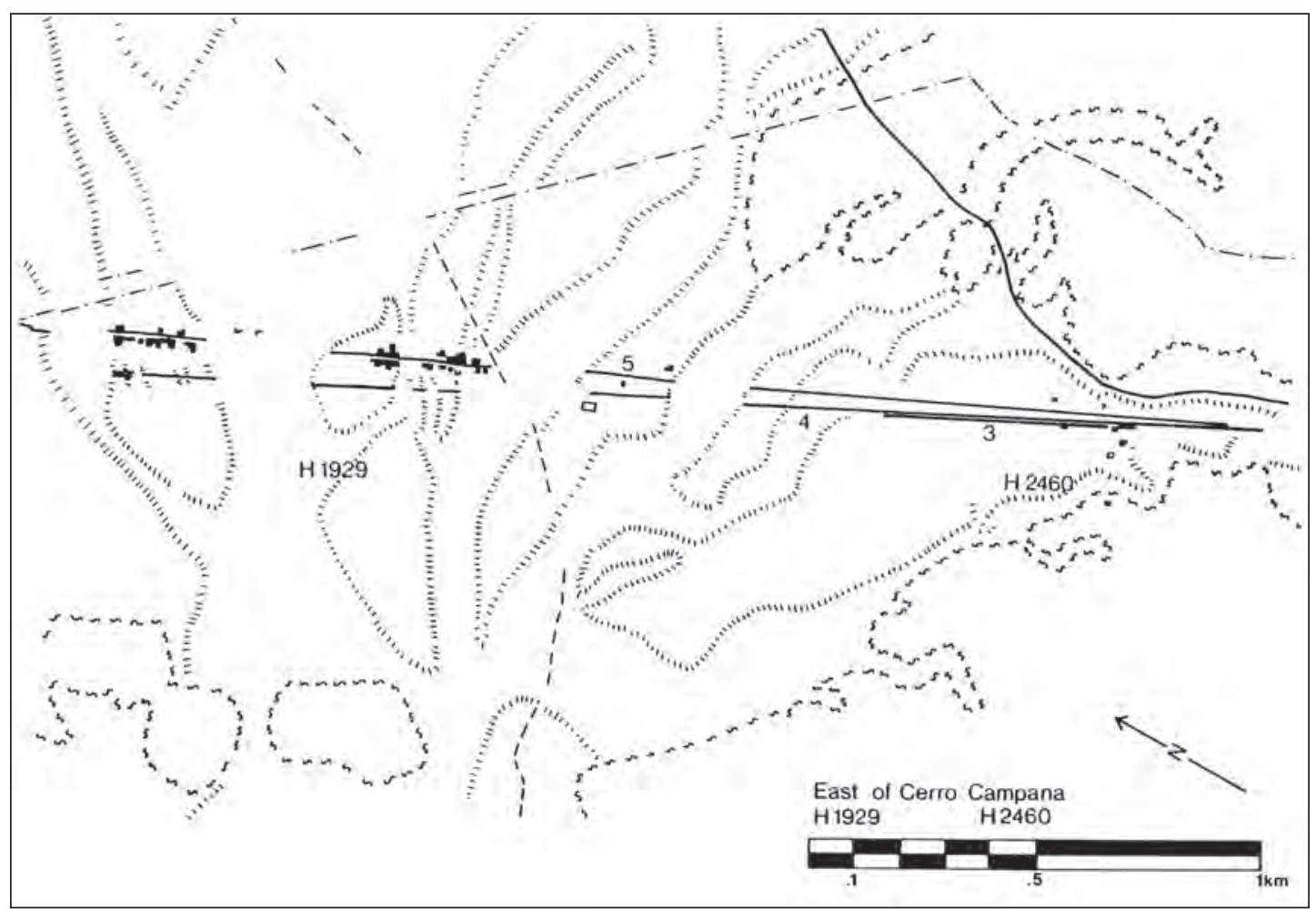

Figura 12. Caminos prehispánicos entre Cerro Campana y Cerro Cabras (Beck 1979: Fig. 15).

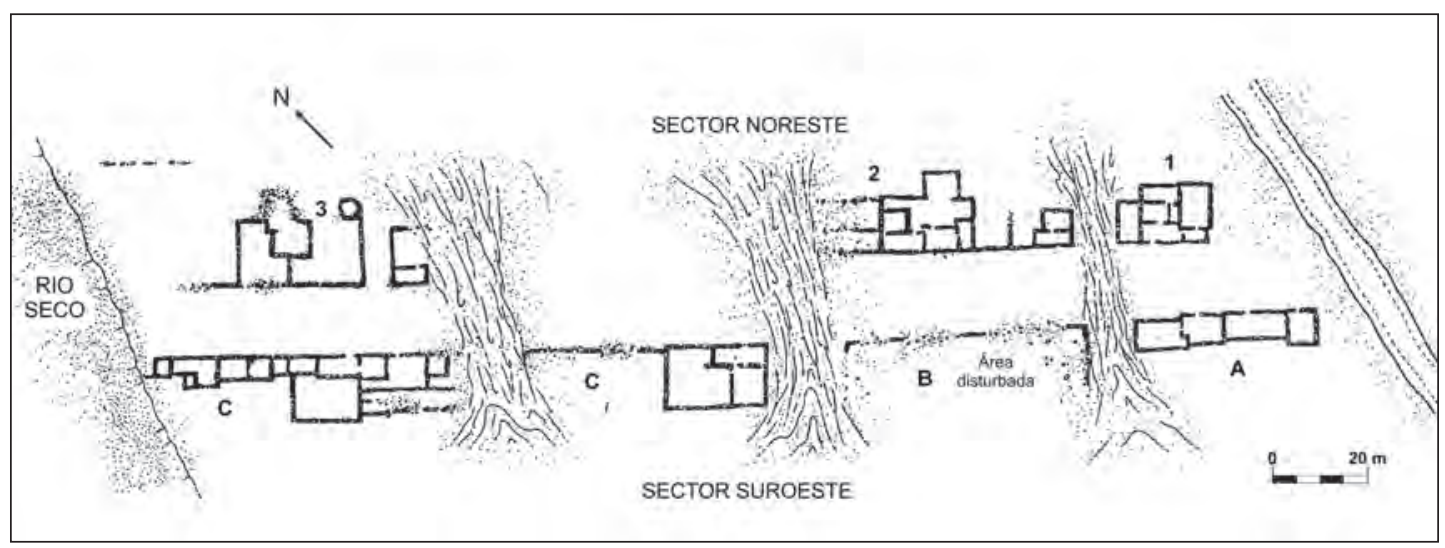

Figura 13. Sitio Moche de Río Seco (Deza y Rodríguez 2003: 266).

$170 \mathrm{~m}$ al este del Montículo 1 y delimitado por muros de cantos rodados unidos con barro (Barr 2000). El piso de esta estructura presentó áreas de quema, concentraciones de desechos orgánicos y una serie de cántaros domésticos de cuello convergente o recto-evertido. Un elemento adicional de esta construcción fue el entierro de un individuo juvenil, sepultado en posición flexionada en una esquina del ambiente (Barr 2000: 18-19, Fotos 6a-b, 7). Las vasijas halladas en el recinto han sido descritas como perteneciente al estilo Gallinazo, aunque ciertamente comparte rasgos formales con algunos componentes de la cerámica domestica de Huacas de Moche. 


\section{Entierros Virú/Gallinazo documentados por la UNT}

Las investigaciones de la UNT en Pampa La Cruz condujeron al hallazgo de dos contextos funerarios interpretados como pertenecientes a una población pre-Moche, identificada como Gallinazo o Virú. El primer entierro fue excavado por Sánchez y Tinta (1990) y consistió en una fosa definida por un muro de piedras, que contenía los cuerpos de dos adultos y ofrendas cerámicas. Ambos individuos carecían del cráneo, pero sus cuerpos se hallaban articulados y dispuestos en sentido norte-sur. La fotografía publicada de este contexto (Barr 2000: Foto 5) permite apreciar que uno de ellos yacía casi completamente extendido, conservando sus vértebras cervicales y con los brazos a los lados del cuerpo, mientras que el segundo personaje estaba apoyado sobre su lado derecho, con las piernas semiflexionadas, el brazo derecho junto al torso y el brazo izquierdo en ángulo recto sobre el pecho. También se observa la presencia de una mandíbula ubicada en proximidad al primer individuo.

El segundo contexto fue registrado por Barr y Sachún pertenecía a un individuo juvenil inhumado junto a una de las esquinas interiores del «recinto abastecedor» (Barr 2000: Figs. 4 y 5). Este entierro se caracterizó por presentar el fondo de un cántaro domestico como soporte para el cuerpo del individuo, el cual presentaba las piernas fuertemente plegadas hacia el lado izquierdo del torso y los brazos doblados en ángulo recto sobre el abdomen (Barr 2000: Foto 7). Aunque estos contextos funerarios fueron identificados como pertenecientes a la manifestación Gallinazo, esa interpretación ciertamente amerita una reevaluación de las particularidades del tratamiento mortuorio, asociación estratigráfica y filiación estilística de las ofrendas, necesidad que hace extensiva a la presentación completa de los materiales registrados en el relleno de las tumbas.

\section{Entierros Moche IV en Huanchaco documentados por el CCMVP}

En 1969 un grupo de contextos funerarios Moche IV fue excavado en la Zona B de Pampa La Cruz (Donnan y Mackey 1978: 17, 188-207). Estos entierros se hallaban al interior de un conjunto arquitectónico construido con piedras y mortero de barro, localizado a $50 \mathrm{~m}$ al noreste del recinto publicado por Barr (2000: Fig. 5) y que contuvo diversos «depósitos» rectangulares, un corredor central y una serie de grandes vasijas domesticas. A pesar que la ocupación Moche en Huanchaco se prolongó entre las Fases III y IV (Donnan y Mackey 1978: 189) estos entierros presentaron ofrendas cerámicas solo de la Fase IV.

Tumbas de cámara: Las dos cámaras funerarias registradas en 1969 fueron elaboradas con muros de cantos rodados que revestían grandes fosas que rompieron los pisos de barro del conjunto hasta alcanzar una capa de arena estéril. La primera cámara (M-IV 20) midió 1,90 m por 0,75 m, y se orientaba de NE a SW (Donnan y Mackey 1978: 190-191). La cubierta estuvo formada por varas de madera que sostuvieron los adobes que recubrían la boca de la cámara. El individuo sepultado fue una mujer adulta, envuelta en textiles, posiblemente embarazada al momento de su muerte y dispuesta en posición extendida con el torso apoyado sobre su lado derecho y la cabeza orientada al NE (Fig. 14). Las ofrendas mortuorias incluyeron un cántaro pintado con diseños escalonados y un aro de cobre colocado al interior de la boca.

La segunda cámara (M-IV 25) contenía las osamentas de un adulto probablemente masculino como personaje central, una mujer adulta (M-IV 28) y dos fetos (M-IV 26 y 27) (Fig. 15). La estructura presentaba eje NW-SE, y medía $2 \mathrm{~m}$ por 0,75 m, con 0,60 $\mathrm{m}$ de profundidad (Donnan y Mackey 1978: 200-207). El individuo principal fue sepultado en posición extendida y con la cabeza orientada al SE, presentando objetos de cobre en la boca y en las manos, hallándose flanqueado por los neonatos. Los restos desarticulados del personaje femenino se hallaban sobre el muro sur de la cámara, faltando el cubito y el radio de ambos brazos, el húmero y el omoplato izquierdos, el sacro, vertebras y ambas manos. Las manos de la mujer pudieron ser colocadas como ofrendas al interior de la cámara, la cual presentó tres manos articuladas adicionales (posiblemente seccionadas aun con tejidos musculares), dos de ellas dispuestas junto al personaje central (Donnan y Mackey 1978: 206). 
El ritual funerario en esta tumba se inició con la dispersión de arena fina sobre el fondo de la cámara. Tras colocarse los cuerpos del hombre y los neonatos sobre esterillas se dispusieron como ofrendas las cabezas y extremidades de dos camélidos, tres manos humanas cortadas, pequeños animales dispuestos junto al muro oeste, y diez piezas de cerámica fina. La mayoría de vasijas, los cráneos de camélido, y una de las manos seccionadas fueron colocados en el lado sur de la tumba. La cubierta de la estructura mortuoria incluía varas de madera y cañas. Los huesos desarticulados de la mujer fueron colocados sobre el borde de la tumba, al exterior de la cubierta de caña y estuvieron acompañados por el cráneo de un camélido y una botella de asa estribo.

Entierros en fosa: En otra parte del conjunto arquitectónico se registraron cuatro tumbas de fosa conteniendo a individuos orientados de NW a SE y con los cráneos dispuestos hacia el Sur (Donnan y Mackey 1978: 192-199). Dos tumbas correspondieron a un hombre y una mujer de edad avanzada. El varón (M-IV 22) presentaba las manos sobre la pelvis y estuvo envuelto en textiles y juncos no entretejidos con el rostro cubierto por un tejido fino, presentando como ofrendas láminas de cobre sobre la nariz y en una de las manos. La mujer (M-IV 21) estuvo envuelta en una esterilla, presentaba los antebrazos doblados en ángulo recto sobre el abdomen. Careció de ofrendas de cobre, presentando tres mates (uno de ellos en posición invertida y cubriendo parte del cráneo) y una botella de pico recto y asa lateral, colocada junto a su cabeza. Las otras tumbas (M-IV 23 y M-IV 24) correspondieron

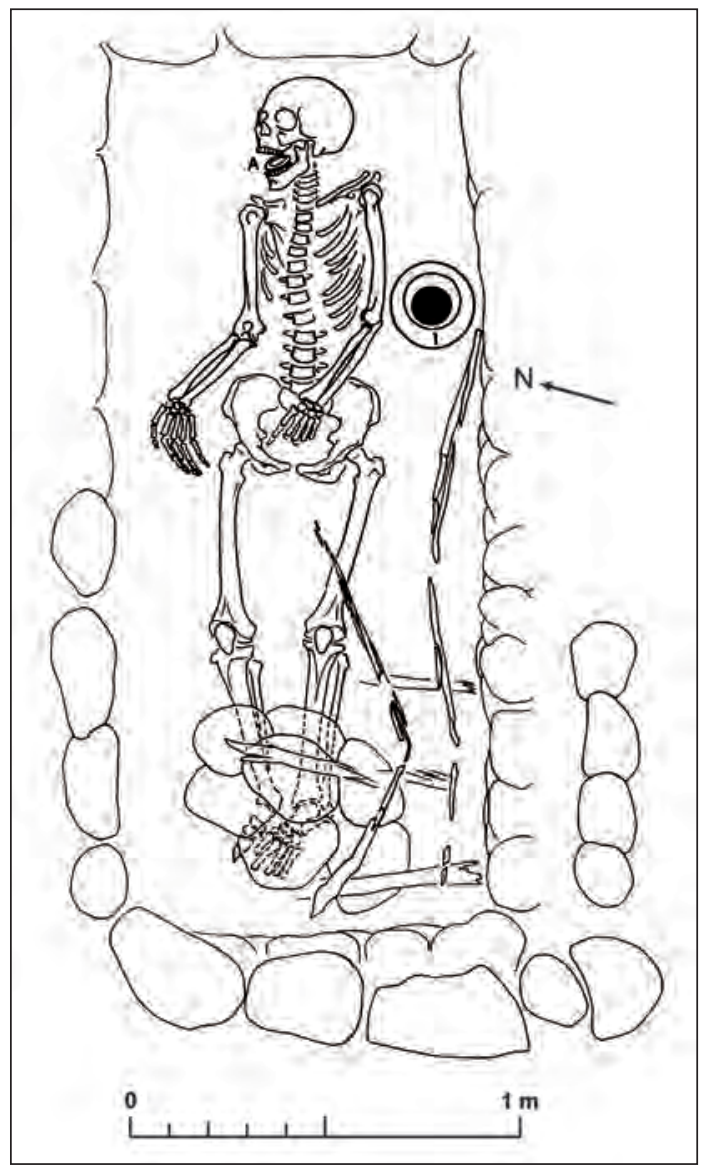

Figura 14. Entierro M-III 20 de Huanchaco (adaptado de Donnan y Mackey 1978: 191).

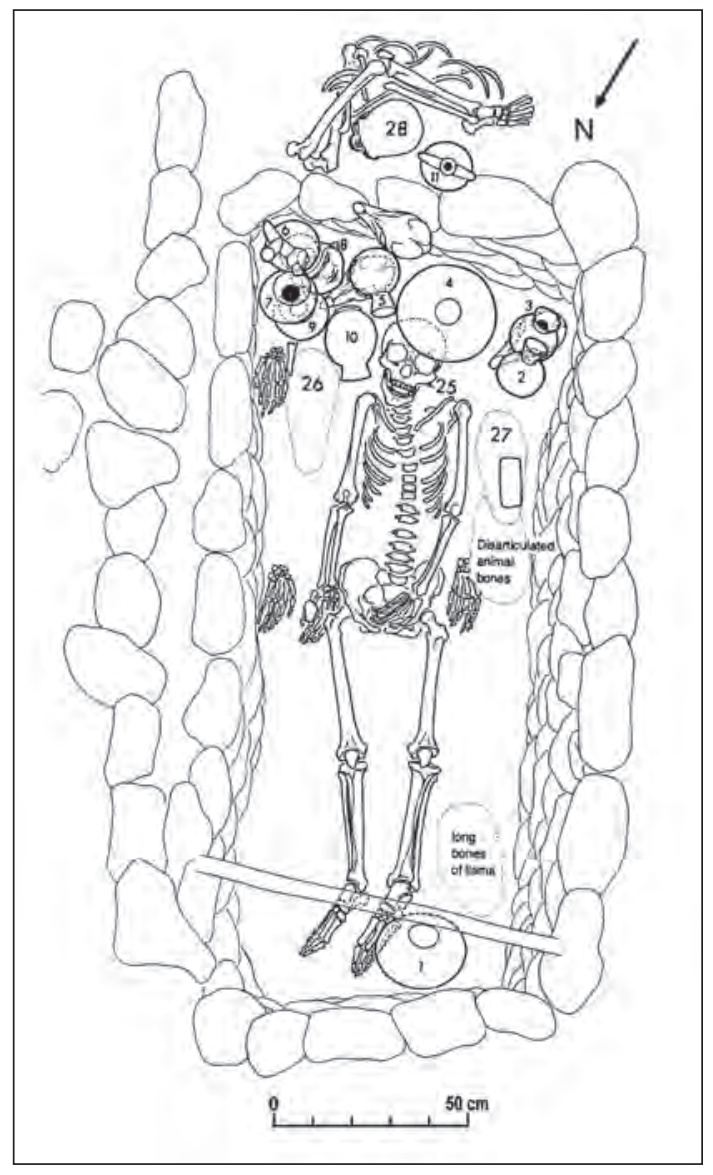

Figura 15. Entierro M-IV 25 de Huanchaco (adaptado de Donnan y Mackey 1978: 201). 
a individuos infantiles, que presentaron envoltorios de textiles y juncos, fragmentos de cobre sobre el cuerpo y ofrendas de vasijas decoradas.

\section{Comparación de contextos funerarios}

La disponibilidad y posición de objetos de cobre en la tumba Moche de Caballo Muerto no difiere de aquella observada en Huanchaco, encontrándose en ambos sectores piezas de cobre laminado dispuestas junto al cuerpo de los individuos sepultados. Las ofrendas cerámicas en ambos sitios también muestran una clara relación con la producción de alfarería fina de huacas de Moche (Donnan y Mackey 1978: 92-187; Chapdelaine 2003: Lám. 22.4), presentándose claras afinidades estilísticas entre la cerámica funeraria Moche IV de todos estos asentamientos, semejanzas que incluyen motivos iconográficos como la soga pintada, diseños serpentiformes y figuras en S o escalonadas. La variabilidad en la posición de los cuerpos es difícil de evaluar debido al tamaño reducido de la muestra. La orientación de los cráneos al SE, SW y NE registradas en el litoral y en Caballo Muerto también aparecen en la muestra mucho más extensa de contextos funerarios de Huacas de Moche (Tello et al. 2003: Cuadro 5.1), existiendo en todos los grupos predominio en la posición extendida dorsal de los cuerpos y en la disposición de la cabeza hacia el sur.

\section{Evolución sociopolítica Moche en CONTEXTo local}

\subsection{Periodo Inicial y Horizonte Temprano (1600 - circa 100 a.C.)}

Durante los dos primeros milenios a.C. la margen norte del valle bajo de Moche presentó ocupaciones permanentes en proximidad al valle medio y en el litoral de Huanchaco (Briceño y Billman 2008; Nesbitt et al. 2010; Pozorski 1976, 1982, 1987; Pozorski y Pozorski 1979). La existencia de una larga secuencia ocupacional en la zona del litoral a partir de 2000 a.C. indica la importancia para esa zona de los pescadores y agricultores de hoyas húmedas en la formación de las primeras entidades sociopolíticas complejas locales (Moseley y Deeds 1982: 35-36).

Los canales Cupisnique en la margen norte del valle bajo habrían continuado en uso durante la ocupación Salinar (200 a.C.-200 d.C.), la cual ha sido documentada solo en Huanchaco (Barr 2000: 1415, 17; Donnan y Mackey 1978; Piminchumo 2001) y Caballo Muerto (Chauchat y Guffroy 2003). Debe recordarse que el bajo número de evidencias Cupisnique y Salinar en la banda norteña del valle bajo de Moche podría deberse más al posterior uso agrícola intensivo de la llanura, las acumulaciones aluviales y eólicas y la escasez de excavaciones que la falta de ocupación del área durante ese tiempo. En cualquier caso, la margen norte del valle bajo carece de un sitio comparable a Cerro Arena en el lado sur del valle (Brennan 1980), con la mayor parte del área pudiendo haber presentado una población escasa y/o un patrón demográfico disperso en comparación a la margen sur del valle bajo y el valle medio.

\subsection{Periodo Intermedio Temprano e inicios del Horizonte Medio (100 - 750 d.c.)}

La existencia de elementos comunes en la cultura material de los diversos sitios del área entre 400 y 700 d.c. ha llevado a considerar la existencia de un sistema sociopolítico local caracterizado por la presencia de patrones de producción artesanal y prácticas ceremoniales compartidas. Sin embargo, esta perspectiva es el resultado de la apreciación diacrónica del proceso cultural del área, la cual alcanzó un grado mayor de integración solo hacia 500 d.c., luego del incremento demográfico en la margen norte del valle bajo y la centralización política en huacas de Moche.

Aunque los canales La Mochica y Vichanzao aparecen asociados a sitios con una cultura material reconocida en términos generales como Moche, se hace necesario recordar la presencia en el litoral de Huanchaco de evidencias cerámicas y funerarias Salinar y Virú/Gallinazo. Debe recordarse que los tipos cerámicos Castillo Modelado y Castillo Inciso corresponden a formas de vasijas mayormente do- 
mesticas, evidenciando pertenecer a un conjunto de tradiciones alfareras regionales. Debido al bajo número de publicaciones sobre el hallazgo de piezas de cerámica con pintura negativa en Pampa La Cruz y la falta de fechados radiocarbonicos aún no es posible aun definir si todas esas evidencias se asociaban a una ocupación no-Moche. Asimismo, debe considerarse que parte de la cerámica Virú/ Gallinazo de Huanchaco pertenece a una ocupación local que formaba parte de un asentamiento más extenso (Barr 2000), el mismo que alcanzó un grado notable de integración con la margen sur del valle bajo hacia mediados y fines del periodo Intermedio Temprano.

A partir de 450 d.C., en Caballo Muerto, las pampas eriazas entre El Porvenir y Río Seco, y en Huanchaco aparecieron asentamientos cuyos pobladores empleaban artefactos cerámicos del estilo Moche. El sitio más importante en términos de monumentalidad física fue huaca Vichanzao. Por su menor extensión y carencia de plataformas, San Idelfonso, Pampas La Esperanza y Río Seco debieron haber ocupado una posición inferior a huaca Vichanzao, estando a cargo de parte del área irrigada y de la ruta Laredo-Huaca Vichanzao-Río Seco-Chicama. La comunidad de pescadores y agricultores de Huanchaco debió representar un tipo particular de asentamiento, con un carácter distintivo dado su rol como proveedor de recursos marinos y su mayor antigüedad frente al resto de sitios del área. ¿Cuál fue el origen de este sistema de asentamientos y cómo funcionó a lo largo de tres siglos? Sin duda, la explotación de nuevos y extensos campos agrícolas fue el principal factor en juego para la población involucrada en el poblamiento de la margen norte del valle bajo de Moche. Durante el periodo Intermedio Temprano el Valle de Moche pudo presentar 13.000 ha de tierras irrigables bajo condiciones optimas (Billman 2002: 380, 384). Contando con 7.000 ha cultivables, la sección baja de la margen norte contenía el 65\% de las tierras agrícolas del sistema (Mosley y Deeds 1982: Tabla 2.1; Billman 2002: 395). Aunque son necesarias mayores investigaciones respecto a la cronología y el patrón de asentamientos en el área, es posible afirmar que entre 450 a 750 d.C. la economía y la distribución poblacional en la sección baja de la margen norte adquirieron un rol gravitante en las estructuras organizativas y de poder de todo el valle.

Las prospecciones y excavaciones en el Valle de Moche indican un proceso de fuerte centralización política a partir del siglo IV d.C. (Bawden 1994; Billman 2002; Chapdelaine 2003: 271-279). El esquema interpretativo vigente señala que la irrigación artificial de la margen norte del valle bajo fue originada por la presión demográfica sobre zonas ya ocupadas del valle y la consolidación del prestigio y poder económico de Huacas de Moche (Billman 2002), un modelo que incorpora la propuesta de una organización local basada en la posesión estatal y el otorgamiento de grandes extensiones de terreno a linajes de elite, asociaciones religiosas o corporaciones de especialistas de ese asentamiento. Este planteamiento se basa en la interpretación de los grandes canales de irrigación como resultado del interés de una organización sociopolítica compleja por ampliar su base económica. Los sitios locales con arquitectura monumental son considerados en esta perspectiva como evidencia del tributo laboral de distintas comunidades ante una autoridad central que auspiciaba y dirigía la construcción de monumentos públicos.

En su análisis de la relación entre sistemas de irrigación y organización política prehispánica del valle de Moche, Billman (2002: 393) señaló que la construcción de los grandes canales de la margen norte no fue un factor causal de la centralización política en el valle bajo de Moche hacia el siglo IV d.C., ello debido a la representatividad menor de materiales Moche III (el tiempo supuesto de consolidación del poder político de Huacas de Moche y de asimilación o retiro de las poblaciones de filiación serrana del valle medio) frente a los del estilo Moche IV. Según Billman (2002: 392, 395) la expansión agrícola en la margen norteña del valle bajo ocurrió mayormente durante la Fase Moche IV cuando los dirigentes del valle habrían iniciado la movilización de la fuerza laboral rural como una forma de consolidad su capacidad económica y prestigio antes de emprender un programa político más ambicioso de nivel regional, siendo por lo tanto un fenómeno posterior a la consolidación efectiva del poder político de los gobernantes de huacas de Moche. 
La propuesta de Billman incluye una modalidad de tributo pagada según el ciclo anual de las cosechas u otorgada en forma de servicios por 12.700 a 18.200 agricultores dependientes políticamente de huacas de Moche (Billman 2002: 395), ampliando de esta manera la capacidad de los líderes de ese asentamiento para desarrollar a gran escala prácticas de reciprocidad ceremonial y un eventual dominio político y económico sobre otras entidades sociopolíticas. Esa propuesta incorpora el tema del grado de interdependencia entre autoridades y grupos de trabajadores encargados de ampliar la frontera agrícola, un punto aún difícil de evaluar debido al menor énfasis puesto en las dos últimas décadas en el estudio de asentamientos menores y áreas de producción agrícola en el propio valle bajo de Moche. Debe recordarse que los proyectos de intensificación de la producción agrícola han sido señalados como una característica de diversas entidades sociopolíticas andinas, apareciendo en casos tan diversos como los cultivos en camellones y waru-waru de Tiwanaku (Kolata 1993) y las irrigaciones en Lacramarca por los Moche de Santa (Chapdelaine y Pimentel 2001, 2002) y la margen norte del valle bajo de Moche por los Chimú (Moseley y Deeds 1982). En esos casos se ha propuesto que la producción agrícola en las nuevas áreas cultivables estuvo dedicada al expendio de los grupos dirigentes y solo en menor proporción al consumo de las comunidades directamente involucradas en la producción agrícola. La expansión agrícola Moche en la margen septentrional del valle bajo de Moche ciertamente no fue motivada por una necesidad de complementariedad ecológica, dada la redundancia de recursos entre esa área y otras partes del valle bajo y medio.

La existencia de un control territorial Moche discontinuo fue propuesta inicialmente por Shimada (1987: 134-135). Los nuevos datos de la sección meridional de la Costa Norte, en particular de los valles de Santa (Chapdelaine 2008; Chapdelaine y Pimentel 2000, 2001) y Virú (Bourget 2010), tienden a consolidar esta idea, reorientándola hacia un dominio hegemónico discontinuo de huacas de Moche sobre la sección meridional de la Costa Norte, con sectores controlados por grupos autónomos tanto Moche como de identidades étnicas distintas. Por su parte, los estudios desarrollados en Santa han demostrado que la interacción política del valle bajo de Moche con esa área alcanzó un grado notable de complejidad e intensidad entre los siglo IV y V d.C. (Chapdelaine 2010). Considerando la escasez de fechados para la margen norte del valle bajo de Moche y el reconocimiento de una presencia regional Moche extensiva pero discontinua desde circa 350 d.c. (con fuertes vínculos entre Huacas de Moche y el valle bajo de Santa, ver Chapdelaine et al. 2010), la propuesta relación causal entre la emergencia de una organización centralizada en huacas de Moche y la ampliación del sistema hidráulico VichanzaoLa Mochica deberá ser contrastada con la relación cronológica entre esos eventos.

La irrigación de la parte baja del Valle de Moche durante la segunda mitad del periodo Intermedio Temprano debió implicar un factor organizativo determinante pero aún poco comprendido: la interacción entre las poblaciones del valle bajo y aquellas del valle medio, quienes se hallaban en proximidad directa a las bocatomas de los canales de irrigación. Las disputas sobre derechos de uso de aguas entre ambos grupos pudieron ocurrir sobre todo en tiempos de sequía, cuando los campesinos de la zona alta podían aprovechar en mayor grado las escasas descargas de los canales (Billman 2002). El mantenimiento del extenso sistema agrícola Moche en la margen norte del valle bajo de Moche pudo haber incidido en la evolución de una estructura administrativa interzonal relacionada al manejo de los canales de irrigación y a la redistribución de la producción agraria entre las poblaciones implicadas. Tal estructura administrativa debió haber experimentado cambios entre los siglos VII y VIII d.C. cuando el ámbito geográfico de los canales pasó a hallarse dividida entre el sector del valle medio dominado por Galindo -un centro urbano poseedor de edificaciones públicas y un estilo iconográfico distintivo- (Bawden 1982, 2001) y el valle bajo, este último vinculado a la entidad de huacas de Moche.

La perspectiva actual sobre la formación del sistema hidráulico en la margen norte del valle de Moche acentúa el rol director del estado, vinculando la ampliación de los canales al fortalecimiento progresivo del poder político y económico de los líderes de Huacas de Moche. Pero no debe descartarse que en algunos momentos, como durante la emergencia del poder de Galindo y las transformacio- 
nes en el sistema político Moche IV de Huacas de Moche señaladas por Uceda (2008), varios sectores de la margen norte del valle bajo fueran controlados por jerarcas locales con autonomía política temporal a través del control de los canales del área.

\subsection{La ocupación terminal Moche de la margen norte del valle bajo de Moche}

La ocurrencia a fines del siglo VI d.C. de los fenómenos de El Niño y cambios climáticos, propuesta en base al análisis de muestras de hielo del nevado Quelccaya (Cusco) y diatomeas en depósitos lacustres de Ecuador, indica una sucesión de periodos fríos y una severa sequía en la Costa Norte entre 562 y 594 d.C. (Moseley 1992: 209; Shimada et al. 1991). Durante esas décadas la población regional habría enfrentado periodos de alteración climática y deterioro de la infraestructura agrícola (Moseley 1992: 211; Moseley y Deeds 1982: 37, 47). No obstante, estas condiciones medioambientales no ocasionaron el abandono de Huacas de Moche, aunque es probable que incidieran en los cambios que sucedieron entre 600 y 650 d.C. al interior de este centro urbano, cambios que incluyeron la clausura del sector más antiguo de huaca de la Luna y el crecimiento del área residencial y huaca del Sol (Chapdelaine 2000; Gamboa 2005: 211; Uceda 2008).

La visión de los años 80 del abandono de Huacas de Moche hacia 600 d.C. ha sido reemplazada en la última década por un cuadro interpretativo basado en un mayor número de fechas radiocarbonicas y correlaciones estratigráficas y arquitectónicas. La comparación de fechados radiocarbónicos de huacas de Moche y Galindo evidenciaría la coexistencia entre 600 y 750 d.C. de las entidades sociopolíticas del valle bajo y el valle medio de Moche, con ambos grupos mostrando estilos emblemáticos distintivos y orientaciones diferentes en organización socioeconómica e ideología. Los nuevos datos evidencian la prolongación de la ocupación de huacas de Moche hasta mediados del siglo VIII d.C., indicando que la fase final de ese asentamiento habría sido contemporánea con el apogeo de Galindo, el principal asentamiento Moche V del valle medio (Bawden 1982, 2001; Chapdelaine 1998: 114, 2000: 134, 137-139; Lockard 2008: 278-281). ${ }^{3}$

La cerámica fina Moche V es un componente minoritario en huaca Vichanzao (Pérez 1994: 229) San Idelfonso (Gamboa y Nesbitt 2010: Figs. 8b-c), y Pampas La Esperanza (Cossio et al. 1997), indicando la interacción de esos sitios con el valle medio. Un fragmento de botella de asa estribo registrado en Pampas La Esperanza (Cossio et al. 1997: Fig. 20) muestra un diseño pintado similar a los registrados en la cerámica fina Moche V de Galindo (Lockard 2008: Fig. 7). En el caso de San Idelfonso, ya se señaló previamente el registro de cerámica fina y figurinas de clara afiliación al estilo Moche V. La aparición de estos elementos en los sitios del valle bajo norteño puede ser interpretada como evidencia adicional de la contemporaneidad entre la ocupación Moche IV tardía de huacas de Moche y la ocupación Moche V de Galindo sugerida por los fechados de C-14 de ambos asentamientos. Dentro del modelo de interacción zonal que proponemos, los materiales Moche $\mathrm{V}$ registrados en los sitios del valle bajo habrían sido introducidos en la zona como bienes de intercambio desde el valle medio y Galindo. Sin embargo, el acceso de la población de la margen norteña del valle bajo a la producción artesanal Moche V de Galindo no debe hacernos excluir la ocurrencia de conflicto entre ambas zonas, especialmente por el control de recursos hídricos y tierras irrigables, un aspecto que contribuiría a explicar la presencia de grandes murallas de piedra y adobe edificadas durante este tiempo en sitios como San Idelfonso, cerros La Virgen y San Lorenzo en Caballo Muerto, y el propio Galindo. ${ }^{4}$

3 Una perspectiva distinta sobre la relación cronológica entre los sitios primarios Moche del Valle de Moche ha sido presentada por Billman y Briceño (2012).

4 La muralla de San Idelfonso (Gamboa 2006, 2010) pudo formar parte de la demarcación territorial de las comunidades del valle bajo, sirviendo como manifestación del control ejercido sobre el espacio geopolítico local por los grupos asentados en el curso del Canal Vichanzao. Ver también Piminchumo y Gálvez 2003 para una propuesta distinta sobre la función de las murallas. 
El eventual despoblamiento del área irrigada por el canal Vichanzao en la segunda mitad del Horizonte Medio es indicado por la escasa presencia de materiales Chimú Temprano. Siglos después, una nueva expansión agrícola en la margen norte del valle bajo de Moche sucedió como consecuencia de la ampliación de los canales primarios por los Chimú. El límite de la extensión de esas versiones tardías de los canales habría sido alcanzado antes de 1300-1350 d.C., tiempo en el cual el área agrícola experimentó una reducción gradual tras varios periodos de lluvias torrenciales. Según Pozorski (1987: 112), la máxima expansión de los canales Chimú en la banda norte del valle bajo fue anterior al periodo de conquistas regionales Chimú. A partir de los estudios del PRA se determinó que después de 1300 d.C. y en coincidencia con una etapa de conquistas regionales los Chimú continuaron operando solo los canales del valle bajo de Moche que rendían mayor usufructo (La Mochica y la parte alta del Vichanzao), sucediendo una contracción de las tierras agrícolas localizadas al norte de Chan Chan (Mackey 1987: 122). La reducción del área de cultivo en la margen norte del valle bajo de Moche habría sido anterior o paralela al periodo de construcción de los conjuntos arquitectónicos amurallados más extensos y con diseño tripartito en Chan Chan (Pozorski 1987: 114). ${ }^{5}$

El denominado «colapso agrario Chimú» ha sido considerado un factor catalizador en el cambio en las estrategias políticas y económicas que condujeron al poder regional de esta entidad prehispánica tardía (Moseley y Deeds 1982: 43; Pozorski 1987: 113, 117-118). El caso prehispánico tardío conduce a preguntarnos sí durante el periodo Moche sucedió una reducción del área irrigada por el canal Vichanzao tras la formación de relaciones de dominio e interacción política y económica entre huacas de Moche y otros sectores de la Costa Norte. En el presente no es posible dar una respuesta satisfactoria a esta interrogante.

\section{Comentarios FinAles}

Durante el periodo Intermedio Temprano y la parte inicial del Horizonte Medio se observan los primeros intentos de expandir la frontera agrícola y crear un sistema de asentamientos permanentes en la margen norte del valle bajo de Moche. Esta colonización agrícola estuvo relacionada a ensayos constantes de apropiación y modificación del territorio a través de la edificación de plataformas, muros monumentales, caminos y cursos artificiales de agua. La margen norte del valle bajo experimento entre circa 400 y 750 d.C. un complejo proceso de transformación cultural del paisaje, con una primera fase de ocupación del área irrigada por el canal La Mochica y una fase posterior de expansión de los canales Moro y La Mochica y construcción del canal Vichanzao para irrigar las planicies entre Laredo y La Esperanza. El crecimiento demográfico del área alcanzó su mayor índice en la segunda fase, durante la parte final del periodo Intermedio Temprano y la primera parte del Horizonte Medio, cuando se desarrollaron asentamientos con poblaciones usuarias de los estilos cerámicos Moche IV y, en menor medida, Moche V.

La ampliación de los canales La Mochica y Vichanzao y la aparición de asentamientos de diversa magnitud en las zonas cultivadas pueden ser interpretadas como eventos estrechamente vinculados a la consolidación del control político y económico y a la emergencia de un estado centralizado en huacas de Moche en la margen sur del valle. Sin embargo, la existencia de nuevos y mayores datos sobre los sitios de la banda norte del valle bajo nos conduce a considerar que los estudios arqueológicos en el valle de Moche deberán retomar un enfoque orientado hacia la comprensión de los múltiples procesos locales para comprender plenamente la evolución sociopolítica de esta sección de la Costa Norte. Una aproximación holística a los patrones de asentamiento urbanos y rurales en el valle bajo

5 Las fechas sin calibrar de C-14 para el sitio Chimú de Milagro de San José en Pampas de Río Seco caen entre $1255 \pm 80$ y $1325 \pm 80$ dne (Pozorski 1987: Tabla 2), indicando que ese centro administrativo rural funciono hacia la parte final de la máxima expansión agrícola Chimú en la margen norte del valle bajo de Moche. 
de Moche deberá incluir aspectos como la temporalidad en el uso y abandono de los campos de cultivo, la orientación y capacidad productiva de las nuevas tierras agrícolas, la evolución de los patrones de propiedad comunal y estatal sobre el territorio, y el grado de autonomía de las comunidades locales en el control de los recursos hídricos. Esta nueva perspectiva brindará sin duda nuevos y mayores alcances sobre los cambios en la organización sociopolítica, ideológica y económica que marcaron la historia Moche en esta sección del Valle de Moche.

El desarrollo de obras dedicadas a la expansión agrícola ha sido señalado como una característica de las entidades estatales andinas. Pero desde un punto de vista opuesto, este fenómeno también revela también la alta capacidad organizativa de las comunidades que colonizaron esta parte del valle de Moche. Considerada dentro del análisis de los procesos que estructuraron social, politica y económicamente a los Andes, la ocupación Moche en el área examinada en este artículo proporciona así una valiosa oportunidad para estudiar la relación entre poblaciones rurales y asentamientos principales en un periodo decisivo de la Costa Norte prehispánica.

\section{AdDENDA: CONSERVACIÓN DE SITIOS ARQUELÓGICOS EN EL ÁREA URBANA DE TRUJILLO}

La mayoría de sitios Moche localizados en la margen norte del valle bajo de Moche se encuentran sometidos a un creciente proceso de expansión urbana, que ha implicado tanto la destrucción de las edificaciones prehispánicas como la ocupación del espacio donde se encuentran las evidencias arqueológicas. A partir del año 2008 el área próxima al muro monumental ha pasado a ser ocupada por asentamientos modernos que forman parte del sector denominado Alto Trujillo. A solo unos kilómetros de distancia, la huaca Vichanzao, afectada por saqueadores en la época Colonial y por pobladores en la década de 1980 (Pérez 1994; Rischar et al. 1998), se halla en riesgo de nuevos recortes de su espacio intangible. En ambos casos, al igual que en Pampa La Cruz de Huanchaco y el sitio de Río Seco, la protección de los monumentos arqueológicos será posible solo a través del trabajo conjunto de arqueólogos y autoridades locales como medio para la preservación del patrimonio arqueológico en las áreas de crecimiento de Trujillo metropolitano.

\section{Agradecimientos}

El primer autor desea expresar su agradecimiento a Tomás Campos, Álvaro Castañeda, María Chiroque, Niel Pajuelo, Víctor Piminchumo, Ricardo Toribio, y Percy Vilcherrez, arqueólogos de la Universidad Nacional de Trujillo, por su colaboración en el reconocimiento del sitio San Idelfonso. Santiago Uceda, Claude Chapdelaine, Víctor Pimentel, y Carol Mackey proveyeron de valiosas referencias sobre la arqueología Moche y Chimú de los valles de Moche y Santa. Asimismo, Jason Nesbitt hace presente su gratitud a Belkys Gutiérrez, Segundo Vásquez y al equipo de estudiantes de la Escuela de Arqueología de la UNT por su apoyo a la investigación en Caballo Muerto. 


\section{BiBLIOGRAFÍA}

BANKES, George

1971 Some aspects of the Moche Culture. Tesis doctoral. Institute of Archaeology, London University. Londres.

BARR, Genaro

2000 «Liberación arqueológica en 'La Poza’, Huanchaco». Sian: 11-19.

BAWDEN, Garth

1982 «Galindo: A Study in Cultural Transition during the Middle Horizon». En: M. Moseley y K. Day (eds.) Chan Chan Andean Desert City, pp. 285-320. Albuquerque: University of New Mexico Press.

1994 «La paradoja estructural: la cultura Moche como ideología política». En: S. Uceda y E. Mújica (eds.) Moche propuestas y perspectivas, pp. 389-412. Travaux de l'Institut Français d'Etudes Andines 79. IFEA, FOMCIENCIAS y Universidad Nacional de Trujillo. Lima.

2001 «The Symbols of Late Moche Social Transformation». En:J. Pillsbury (ed.) Moche Art and Archaeology in Ancient Peru, pp. 285- 305. Washington, D.C.: Center for Advanced Studies in the Visual Arts, National Gallery of Art.

BECK, Colleen

1979 Ancient Roads on the North Coast of Peru. Tesis doctoral. Department of Anthropology. University of California. Berkeley.

BENNETT, Wendell

1950 The Gallinazo Group, Viru Valley, Peru. Yale University Publications in Anthropology, 43. New Haven, Connecticut.

BILLMAN, Brian

1996 The Evolution of Prehistoric Political Organizations in the Moche Valley, Peru. Tesis doctoral, University of California, Santa Barbara.

2002 «Irrigation and the Origins of the Southern Moche State on the North Coast of Peru». Latin American Antiquity 13 (4): 371-400.

BILLMAN, Brian y Jesús BRICEÑO

2012 A Social History of the Late Moche Phase in the Moche Valley: Results of Recent Excavations and Settlement Patter Analysis. Articulo presentado en la $31^{\circ}$ Northeast Conference on Andean Archaeology and Ethnohistory. Boston.

BOURGET, Steve

2010 «Cultural Assignations during the Early Intermediate Period. The Case of Huancaco, Virú Valley». En: J. Quilter y L.J. Castillo (eds.) New Perspectives on Moche Sociopolitical Organization, pp. 201-222. Dumbarton Oaks Research Library and Collection. Washington D.C.

BRENANN, Curtis

1980 «Cerro Arena: Early Cultural Complexity and Nucleation in North Coastal Peru». Journal of Field Archaeology 7: 1-22.

BRICEÑO, Jesús y Brian BILLMAN

2008 «Gramalote y el Periodo Inicial en el valle de Moche. Nuevos datos de un viejo sitio de pescadores». Revista del Museo de Arqueología, Antropología e Historia de la Universidad Nacional de Trujillo 10: 175-208.

CASTILLO, Luis J. y Christopher DONNAN

1994 «Los mochicas del norte y los mochicas del sur, una perspectiva desde el valle de Jequetepeque». En: K. Makowski et al. (eds.) Vicús, pp. 143-181. Colección Arte y Tesoros del Perú. Lima: Banco de Crédito del Perú.

CHAPDELAINE, Claude

1998 «Excavaciones en la Zona Urbana de Moche durante 1996». En: S. Uceda, E. Mújica y R. Morales (eds.) Investigaciones en la Huaca de la Luna 1996, pp. 85-115. Facultad de Ciencias Sociales, Universidad Nacional de Trujillo.

2000 «Struggling for Survival. The Urban Class of the Moche Site, North Coast of Peru». En: G. Bawden y R. Reycraft (eds.) Environmental Disaster and the Archaeology of Human Response, pp. 121-142. Maxwell Museum of Anthropology. Anthropological Papers 7. University of New Mexico. Albuquerque. 
2003 «La ciudad de Moche: Urbanismo y Estado». En: S. Uceda y E. Mujica (eds.) Moche. Hacia el final del milenio. Tomo II, pp. 243-285. Lima: PUCP y Universidad Nacional de Trujillo.

2008 «Moche Art Style in the Santa Valley. Between being «a la mode» and developing a Provincial Identity». En: S. Bourget y K.L. Jones (eds.) The Art and Archaeology of the Moche), pp. 129-152. Austin: University of Texas Press.

CHAPDELAINE, Claude y Victor PIMENTEL

2001 La ocupación Moche del valle de Santa. Temporada 2000 del Proyecto Santa de la Universidad de Montreal. Informe remitido al Instituto Nacional de Cultura. Lima.

2002 La ocupación Moche del valle de Santa. Temporada 2001 del Proyecto Santa de la Universidad de Montreal. Informe remitido al Instituto Nacional de Cultura. Lima.

CHAPDELAINE, Claude, Victor PIMENTEL y Jorge GAMBOA

2010 «Arquitectura, ideología y poder en El Castillo de Santa». En: J.F. Millaire y M. Morlion (eds.) Gallinazo: An Early Cultural Tradition on the Peruvian North Coast, pp. 181-206. Cotsen Institute. University of California, Los Angeles.

CHAPDELAINE, Claude Santiago UCEDA, Maria MOYA, Cesar JÁUREGUI y Chanel UCEDA

1997 «Los complejos arquitectónicos urbanos de Moche». En: S. Uceda, E. Mújica y R. Morales (eds.) Investigaciones en la Huaca de la Luna 1995, pp. 71-92. Facultad de Ciencias Sociales, Universidad Nacional de Trujillo.

CHAUCHAT, Claude y Jean GUFFROY

2003 «Sepulturas intrusivas Salinar y Chimú en la Huaca Herederos Chica, Valle de Moche, Perú». Bulletin de l'Institut Français d'Études Andines 32: 293-315.

CHAUCHAT, Claude, Jean GUFFROY y Thomas POZORSKI

2006 «Excavations at Huaca Herederos Chica, Moche Valley, Peru». Journal of Field Archaeology 31: 233-250.

CORDY-COLLINS, Alana

1992 «Archaism or continuing tradition: The Decapitation theme in Cupisnique and Moche iconography». Latin American Antiquity 3(3): 206-220.

COSSIO, Marieta, Mario SALAZAR y Ronald TAFUR

1997 Estudio de la arquitectura Moche en la margen izquierda del Río Seco en La Esperanza al noroeste del valle de Moche. Informe final de prácticas pre-profesionales de Arqueología. Universidad Nacional de Trujillo.

DEZA, Carlos y Marco RODRíGUEZ

2003 Estudio de una aldea moche en el Río Seco, La Esperanza-La Libertad. Revista de la Facultad de Ciencias Sociales de la Universidad Nacional de Trujillo, 6: 265-278.

DONNAN, Christopher

1978 Moche Art of Peru. Museum of Cultural History. University of California, Los Angeles

2003 «Tumbas con entierros en miniatura: un nuevo tipo funerario Moche». En: S. Uceda y E. Mújica (eds.) Moche. Hacia el final del milenio. Tomo I, pp. 43-78. Lima: PCUP y Universidad Nacional de Trujillo.

DONNAN, Christopher y Carol MACKEY

1978 Ancient Burial Patterns of the Moche Valley, Peru. University of Texas Press. Texas.

DONNAN, Christopher y Donna MCCLELLAND

1999 Moche Fineline Paintings. Its Evolutions and Its Artists. Fowler Museum of Cultural History. University of California at Los Angeles.

FOGEL, Heidi

1993 Settlements in Time: A Study of Social and Political Development during the Gallinazo Occupation of the North Coast of Peru. Tesis de doctorado. Department of Anthropology, Yale University.

GAMBOA, Jorge

2005 «Continuidad y cambio en la organización de los espacios arquitectónicos de Huaca de la Luna y Plataforma A de Galindo, costa norte del Perú». Bulletin de l'Institut Français d'Études Andines 34(2): 161-183. 
2006 «La ocupación Moche en San Idelfonso, valle bajo de Moche». Revista del Museo de Arqueología, Antropología e Historia de la Universidad Nacional de Trujillo: 107-120.

GAMBOA, Jorge y Jason NESBITT

2010 «San Idelfonso y la ocupación Moche en la margen norte del valle bajo de Moche, Costa Norte del Perú». Anti. Revista del Centro de Investigaciones Precolombinas, Nº 9: 47-107. Buenos Aires.

HASTING, Charles y Michael MOSELEY

1975 «The adobes of Huaca del Sol and Huaca de la Luna». American Antiquity 40: 196-203.

HOCQUENGHEM, Anne Marie

1987 Iconografía Mochica. Fondo Editorial de la Pontificia Universidad Católica del Perú. Lima.

KOLATA, Alan

1993 The Tiwanaku. Basil Blackwell. Oxford

LARCO, Rafael

1944 Cultura Salinar. Síntesis monográfica. Museo Rafael Larco Herrera. Chiclín.

1948 Cronología Arqueológica del Norte del Perú. Sociedad Geográfica Americana. Buenos Aires.

2001 Los Mochicas. Tomos I y II. Museo Arqueológico Rafael Larco Herrera. Lima.

LOCKARD, Gregory

2008 «A New View of Galindo: Results of the Galindo Archaeological Project». En: L.J. Castillo, H. Bernier, G. Lockard y J. Rucabado (eds.) Arqueología Mochica: Nuevos enfoques, pp. 275-294. Lima: IFEA y PUCP.

2009 «The Occupational History of Galindo, Moche Valley, Peru». Latin American Antiquity 20: 279-302.

MACKEY, Carol

1987 «Chimu Administration in the Provinces». En: J. Hass, S. Pozorski y T. Pozorski (eds.) The Origins and Development of the Andean State, pp. 121-129. Cambridge: Cambridge University Press.

MAKOWSKI, Krzysztof

1994 «Los señores de Loma Negra». En: K. Makowski et al. (eds.) Vicús, pp. 83-141. Colección Arte y Tesoros del Perú. Lima: BCP.

1998 «Cultura material, etnicidad y la doctrina política del estado en los Andes prehispánicos: el caso mochica». En: Actas del IV Congreso Internacional de Etnohistoria, Tomo I: 125-147. Lima: Facultad de Letras y Ciencias Humanas. PUCP.

MENDOZA, Lourdes, Eladia PORTOCARRERO y Laura ZERPA

1989 Análisis de la cerámica Gallinazo de Pampa La Cruz, Huanchaco. Valle de Moche. Informe final de prácticas pre-profesionales de Arqueología. Universidad Nacional de Trujillo.

MILLAIRE, Jean-François y Magali MORLION (eds.)

2010 Gallinazo. An Early Cultural Tradition on the Peruvian North Coast. Cotsen Institute of Archaeology Press. University of California, Los Angeles.

MOSELEY, Michael

1992 The Incas and Their Ancestors. Londres: Thames and Hudson.

MOSELEY, Michael y Eric DEEDS

1982 "The Land in front of Chan Chan: Agrarian Expansion, Reform and Collapse in the Moche Valley». En: M. Moseley y K. Day (eds.) Chan Chan Andean Desert City, pp. 25-54. Alburquerque: University of New Mexico Press.

MUJICA, Elías

1984 «Cerro Arena-Layzón: relaciones costa-sierra en el Norte del Perú». Gaceta Arqueológica Andina 10: 12-15.

NESBITT, Jason

2013 The Reinterpretation of Abandoned Initial Period and Early Horizon Monuments in the Moche Valley, Peru. Articulo a ser presentado en la $78^{\circ}$ Conferencia Anual de la Society for American Archaeology. Honolulu.

2010 «Sacrifice and the Reuse of an Initial Period Monument at Caballo Muerto». Articulo presentado en la $29^{\circ}$ Northeast Conference on Andean Archaeology and Ethnohistory. Madison: Drew University. 
NESBITT, Jason, Belkys GUTIÉRREZ y Segundo VÁSQUEZ

2010 «Excavaciones en Huaca Cortada, Complejo Caballo Muerto, Valle de Moche: Un Informe Preliminar». Boletín de Arqueología PUCP 12:261-286. Lima.

NIALS, Fred. L., Eric DEEDS, Michael MOSELEY, Shelia POZORSKI, Thomas POZORSKI y Robert FELDMAN

1979a «El Niño: The Catastrophic Flooding of Coastal Peru, I». Bulletin of the Field Museum of Natural History 50(7): 4-14. Chicago.

1979b «El Niño: The Catatrophic Flooding of Coastal Peru, II». Bulletin of the Field Museum of Natural History 50(8): 4-10. Chicago.

ONERN (Oficina Nacional de Evaluación de Recursos Naturales)

1973 Inventario, evaluación y uso racional de los recursos naturales de la Costa: Cuenca del Río Moche. Lima.

PÉREZ, Ismael

1994 «Notas sobre la denominación y estructura de una huaca Mochica en Florencia de Mora, Valle de Moche». En: S. Uceda y E. Mújica (eds.) Moche: Propuestas y perspectivas. Actas del Primer Coloquio sobre la cultura Moche. Travaux de l'Institut Français d'Etudes Andines 79. Lima: IFEA, FOMCIENCIAS y Universidad Nacional de Trujillo.

PILLSBURY, Joanne (ed.)

2001 Moche Art and Archaeology in Ancient Peru. Studies in the History of Art 63. Center for Advanced Studies in the Visual Arts, Symposium Papers XL. National Gallery of Art. Washington, D.C.

PIMINCHUMO, Víctor

2001 «Evidencias Salinar en el sector sur de la Iglesia Huanchaco». Sian 10: 20-24.

PIMINCHUMO, Victor, y Cesar GÁLVEZ

2003 «La Muralla de la Cumbre». Sian 14: 18-25.

POZORSKI, Thomas

1976 Caballo Muerto: A Complex of Early Ceramic Sites in the Moche Valley, Peru. Tesis doctoral. Department of Anthropology, University of Texas at Austin.

1982 «Early Social Stratification and Subsistence Systems: The Caballo Muerto Complex». En: M. Moseley y K. Day (eds.) Chan Chan: Andean Desert City, pp. 225-253. Albuquerque: University of New Mexico Press.

1987 «Changing priorities within the Chimú State: the role of irrigation agriculture». En: J. Haas, S. Pozorski y T. Pozorski (eds.) The Origins and Development of the Andean State, pp. 111-120. Cambridge: Cambridge University Press.

POZORSKI, Shelia y Thomas POZORSKI

1979 «An Early Subsistence Exchange System in the Moche Valley, Peru». Journal of Field Archaeology 6: 413-432.

QUILTER, Jeffrey

2002 «Moche Politics, Religion, and Warfare». Journal of World Prehistory 16(2): 145-195.

RAMÍREZ, Eulalia y Maria WONG

1984 Investigaciones arqueológicas en la falda del Cerro Cabras. Informe final de prácticas pre-profesionales de Arqueología. Universidad Nacional de Trujillo.

RAVINES, Rogger y Alejandro MATOS

1983 Inventario de monumentos arqueológicos del Perú, Zona Norte (Primera aproximación). Lima: INC.

RISCHAR, Stefan, Carlos VEGA CÁRDENAS y Miguel VEGA CÁRDENAS

1998 «Las Huacas Bitim y Vichanzao con una mención temprana de «El Mampuesto», Valle de Moche. Bosquejo de una interpretación integral». Sian 5: 22-26.

RODRÍGUEZ SUY SUY, Víctor

1971 Irrigación prehispánica en el Valle de Moche. Centro Nacional de Capacitación e Investigación para la Reforma Agraria. Lima.

SÁNCHEZ, Pilar y Marisa TINTA

1990 Patrón de enterramiento de la cultura Gallinazo en Pampa La Cruz. Informe final de prácticas pre-profesionales de Arqueología. Universidad Nacional de Trujillo. 
SHIMADA, Izumi

1987 «Horizontal and Vertical Dimensions of Prehistoric States in North Peru». En: J. Haas, T. Pozorski y S. Pozorski (eds.) The Origin and Development of the Andean State, Cambridge: Cambridge University Press.

SHIMADA, Izumi, Crystal B. SCHAFF, Loonie G. THOMPSON y Ellen MOSLEY-THOMPSON

1991 «Implicaciones culturales de una gran sequía del siglo VI D.C. en los Andes peruanos». Boletín de Lima 13 (77): 33-56.

STRONG, Duncan y Clifford EVANS

1952 Cultural Stratigraphy in the Viru Valley, Northern Peru: The Formative and Florescent Epoch. Columbia Studies in Archaeology and Ethnology 4. New York: Columbia University Press.

TELLO, Ricardo, José ARMAS y Claude CHAPDELAINE

2003 «Prácticas funerarias Moche en el Complejo Arqueológico Huacas del Sol y de la Luna». En: S. Uceda y E. Mújica (eds.) Moche. Hacia el final del milenio. Tomo I, pp. 151-187. Lima: PUCP y Universidad Nacional de Trujillo.

TOPIC, Teresa Lange

1982 «The Early Intermediate Period and its legacy». En: M. Moseley y K. Day (eds.) Chan Chan Andean Desert City, pp. 255-284. Albuquerque: University of New Mexico Press.

1991 «The Middle Horizon in Northern Perú». En: G. McEwan (ed.) Huari Administrative Structure. Prehistoric Monumental Architecture and State Government, pp. 233-246. Washington, D.C.: Dumbarton Oaks Research Library and Collection.

UCEDA, Santiago

2008 «En busca de los palacios de los reyes de Moche». En: K. Makowski (comp.) Señores de los Reinos de la Luna, pp. 111-127. Lima: BCP.

UCEDA, Santiago y José ARMAS

1998 «An urban pottery workshop at the site of Moche, North Coast of Peru». En: I. Shimada (ed.) Andean Ceramics: Technology, Organization, and Approaches, pp. 91-110. MASCA Research Papers in Science and Archaeology, Supplement to Vol. 15. Philadelphia: University of Pennsylvania Museum of Archaeology and Anthropology.

UCEDA, Santiago, Claude CHAPDELAINE y John VERANO

2008 «Fechas Radiocarbónicas para el Complejo Arqueologico Huacas del Sol y de La Luna: Una primera cronología del sitio». En: S. Uceda, E. Mujica y R. Morales (eds.) Investigaciones en la Huaca de la Luna 2001, pp. 213-223. Trujillo: Patronato Huacas de Moche y Facultad de Ciencias Sociales de la Universidad Nacional de Trujillo.

UCEDA, Santiago y Elías MUJICA (eds.)

1994 Moche. Propuestas y perspectivas. Actas del Primer Coloquio sobre la Cultura Moche. Travaux de l'Institute Français d'Etudes Andines 79. Lima: IFEA, FOMCIENCIAS y Universidad Nacional de Trujillo.

2003 Moche. Hacia el final del milenio. Tomos I y II. Lima: PUCP y Universidad Nacional de Trujillo.

UHLE, Max

1915 «Las ruinas de Moche». Boletín de la Sociedad Geográfica de Lima 30 (3-4): 57-71. Lima.

1976 Sitios tempranos en el Valle de Moche (Costa Norte del Perú). Tesis doctoral. Universidad Nacional Mayor de San Marcos. Lima. 